\title{
Assessment of the seismic behaviour of braced steel storage racking systems by means of full scale push over tests
}

\author{
Alper Kanyilmaz*, Giovanni Brambilla, Gian Paolo Chiarelli, Carlo Andrea Castiglioni \\ Department of Architecture, Built Environment and Construction Engineering, ABC, Politecnico di Milano, Italy
}

\begin{abstract}
Pallet racking systems, made of thin-walled cold formed steel profiles, are commonly used to store va-luable goods and products in the logistics industry. In service conditions, longitudinal (down-aisle) stability of the racks is provided by the flexural stiffness of the demountable beam-upright column connections and base joints. Rack designers usually prefer to avoid bracings for a full accessibility of shelves from both aisles. However, under seismic conditions, typical rack connections cannot often provide sufficient flexural performance in terms of stiffness and strength, which deems necessary to introduce spine (longitudinal) bracings in the down-aisle direction. Yet the racks can only be braced at one of their two longitudinal planes to allow pallet loading from the aisle, which results in an asymmetric horizontal bearing configuration. This combined with their perforated upright columns, and nonstandard beam-upright and base connections make it even more difficult to estimate their complex global seismic performance. Therefore, full scale experimental investigations are strongly needed in order to understand and quantify the global performance of the braced storage racks, and improve their design for seismic actions.

This paper presents the experimental results of the Europe's largest full-scale push-over testing program that has been carried out on racking systems. In particular, experimental global capacity curves of 6 fully-loaded pallet racking specimens with spine bracings, provided by 5 different international rack producers, are presented, discussing the key factors influencing the racks' response, as well as the failure mechanisms of the different rack typologies. Furthermore, behaviour factor (q) values of each specimen are derived from re-analysis of test results. Vulnerability of braced racks to bracing connection failure is demonstrated, highlighting its causes. Design indications are provided in order to guarantee a globally homogenous ductility under seismic actions.
\end{abstract}

\section{Introduction}

Steel storage racks are commonly used to store valuable goods in logistics and commercial warehouses. Their structural components are often made of thin walled perforated profiles to ensure the versatility needed in storing goods. Due to the high competitiveness of logistics industry, they are designed as lightweight as possible to save on steel material costs. Despite the lightness of their structural systems, storage racks carry very high unit loads (in average 8-10 kN per pallet), by far higher than their self-weight, contrary to what happens in usual civil engineering structures.

Classical types of storage racks are well described by Pekoz et al. [1]. Structural system of pallet-racks (Fig. 1) [2] is mainly composed of uprights (vertical members) made of perforated thin

\footnotetext{
* Corresponding author.

E-mail address: alper.kanyilmaz@polimi.it (A.

Kanyilmaz).
}

walled elements, and pallet beams (horizontal members), made of built-up closed sections linking adjacent frames, lying in the horizontal direction parallel to the operating aisle. Diagonal elements (bracings) connect the uprights to each other in the cross-aisle (transversal) direction to form the upright frames, whereas the connections between the uprights and the pallet beam (beam-tocolumn joints) in down-aisle (longitudinal) direction are usually made of proprietary hook-in connectors welded to the pallet beam ends, and engaged into perforated holes in the uprights. Uprights are usually connected to the industrial floor by L shaped components that are connected on the upright base on one leg, and on the floor on the other.

Stability of upright frames in cross-aisle direction is always provided by diagonal elements. On the other hand, in down-aisle direction, rack designers usually prefer avoiding bracings to make the shelves accessible on both sides from two aisles, allowing an efficient loading and unloading of goods in service. However, in high seismic regions, this configuration is usually not adequate to resist strong horizontal loads because of insufficient flexural 


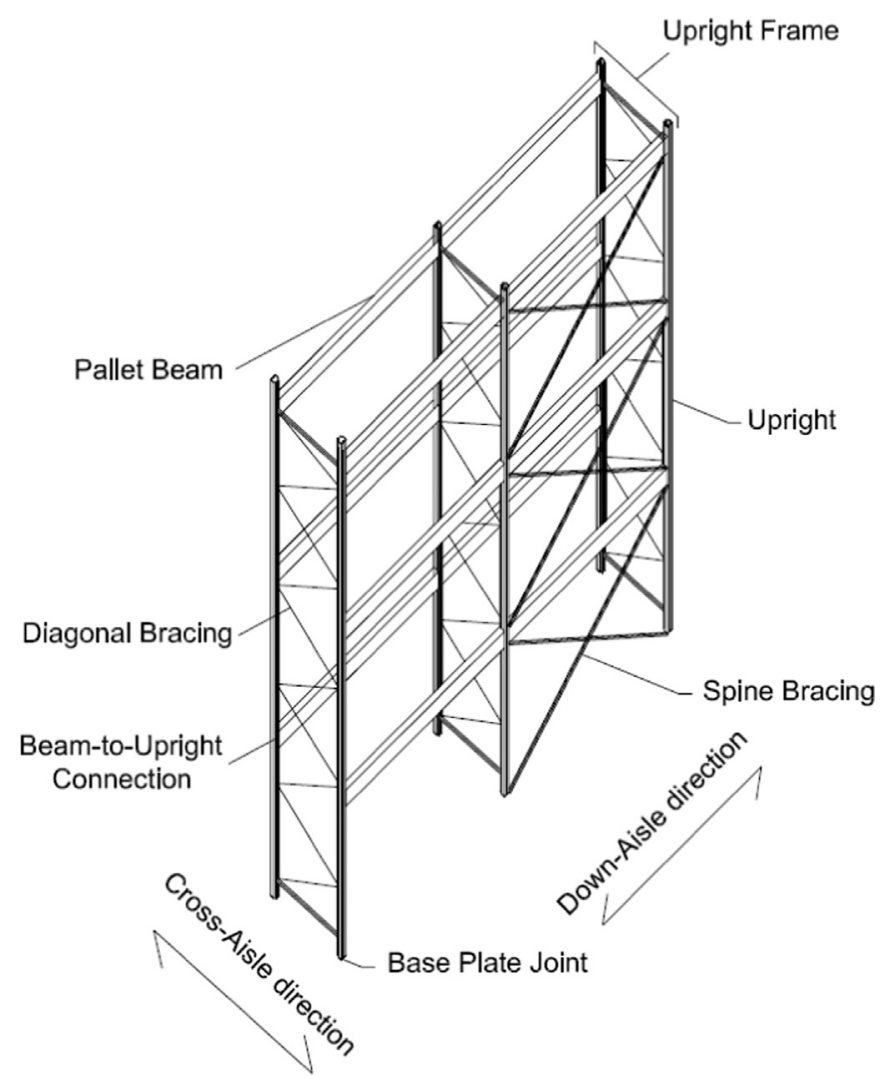

Fig. 1. Typical braced pallet rack configuration [2].

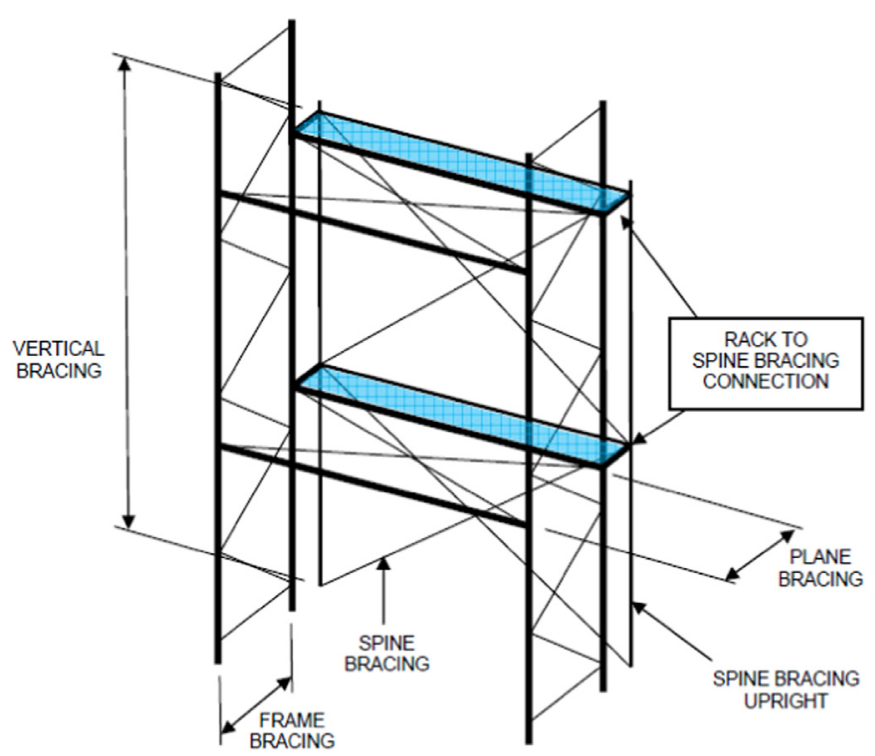

Fig. 2. Spine bracing layout [3].

stiffness of the racks' demountable beam-upright column connections. When high-seismicity is a concern, spine bracings are often used in down-aisle direction. The complex structural configuration of storage racks braced only in one side, in contrast to civil engineering structures in which bracings are placed regularly in all sides, result in a poorly understood seismic behaviour, and should be investigated carefully. In the literature, experimental tests which can reasonably estimate the seismic behaviour of this type of racks are not yet available. For this reason, under the coordination of the authors, a large research group including experts both from academy and rack industry has implemented a research project funded by Research Fund for Coal and Steel (RFCS), where full scale push-over tests have been performed on fully-loaded pallet racking specimens having spine bracings. This paper 


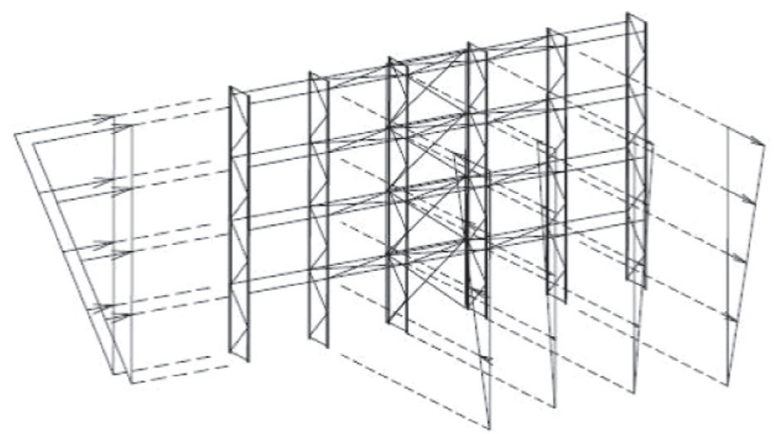

a. Redistribution of longitudinal actions in a braced racking system
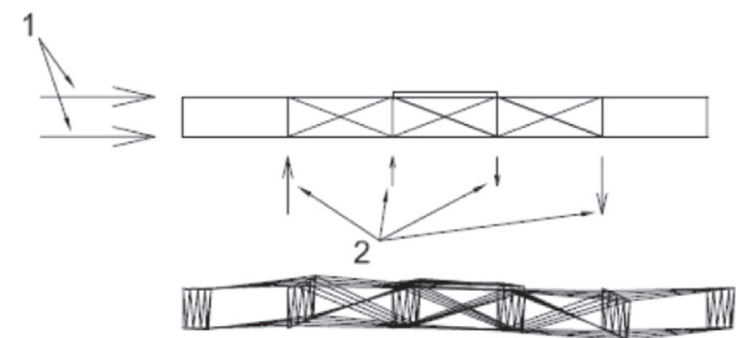

b. Longitudinal (1) and transversal (2) actions

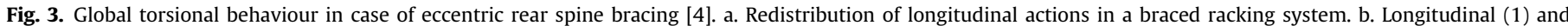
transversal (2) actions.

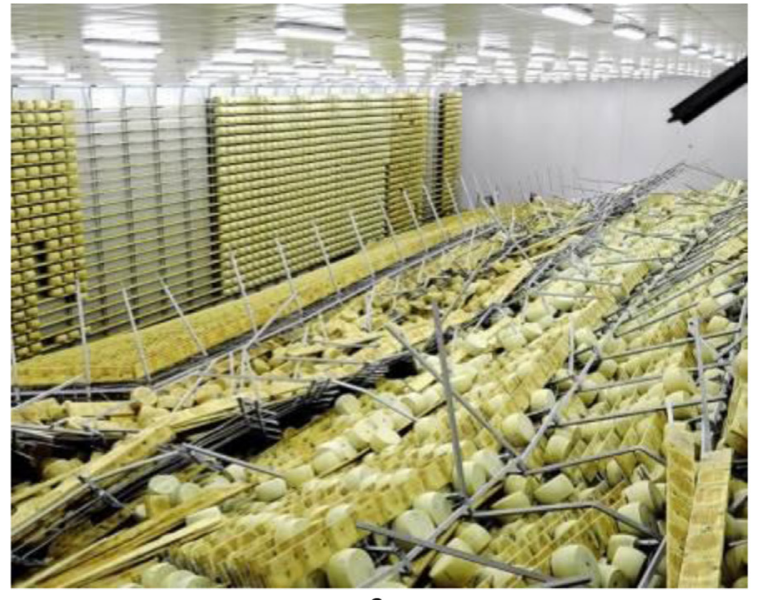

a.
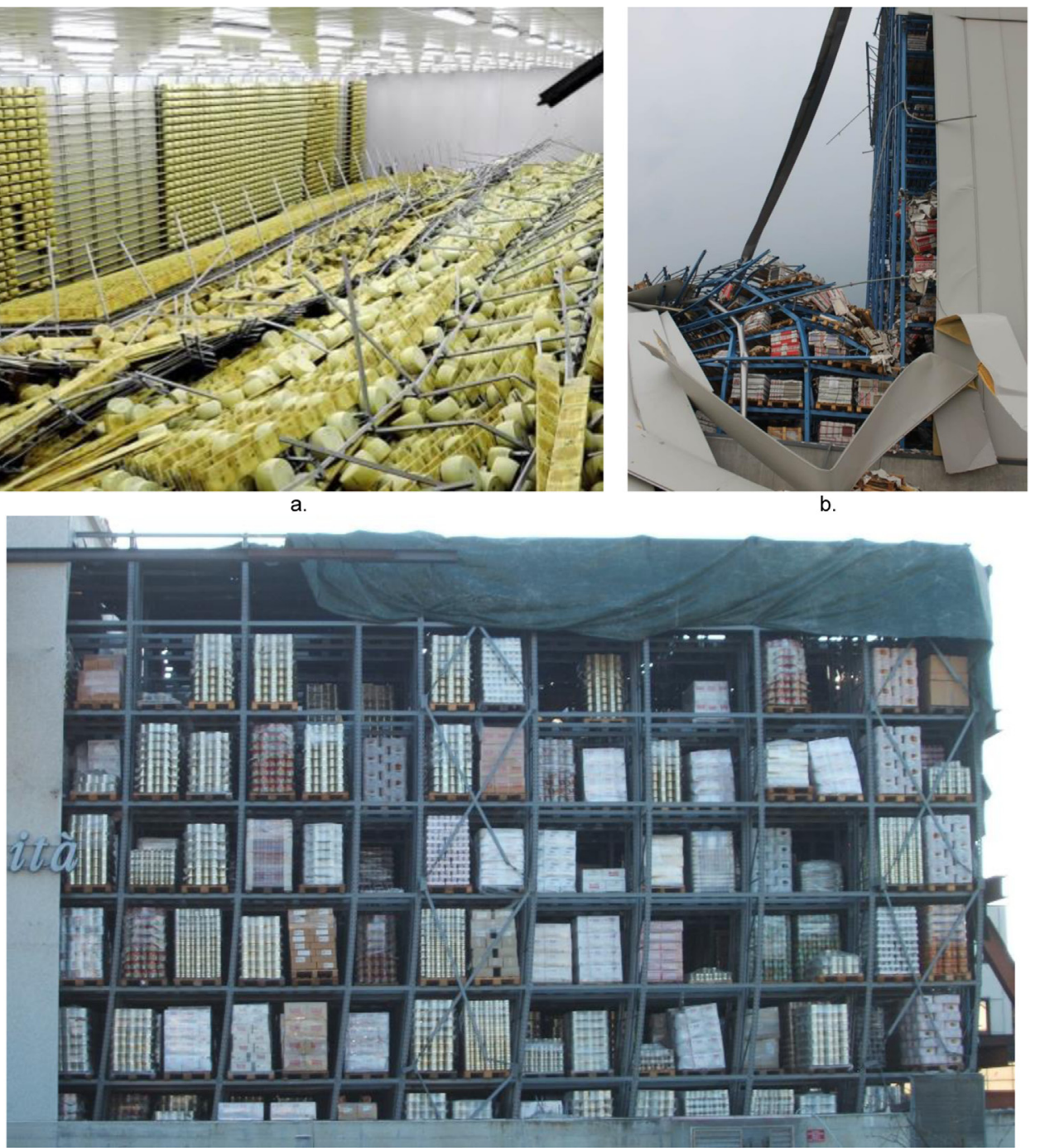

b.

\section{.}




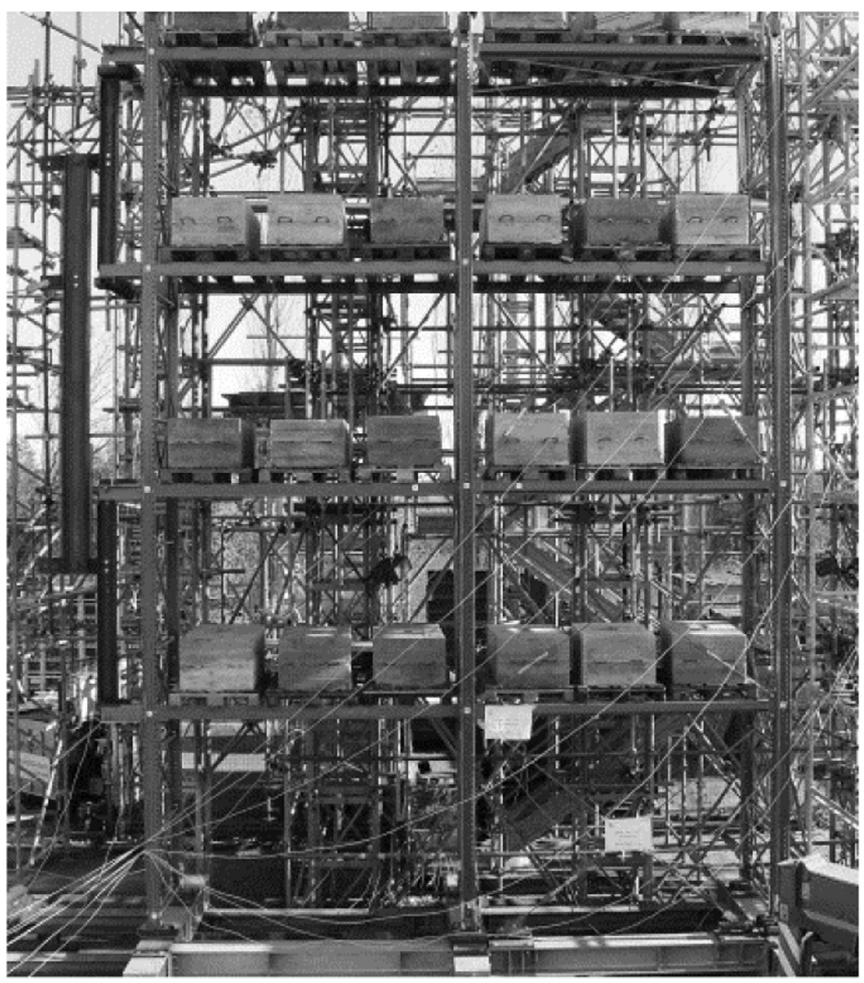

a.
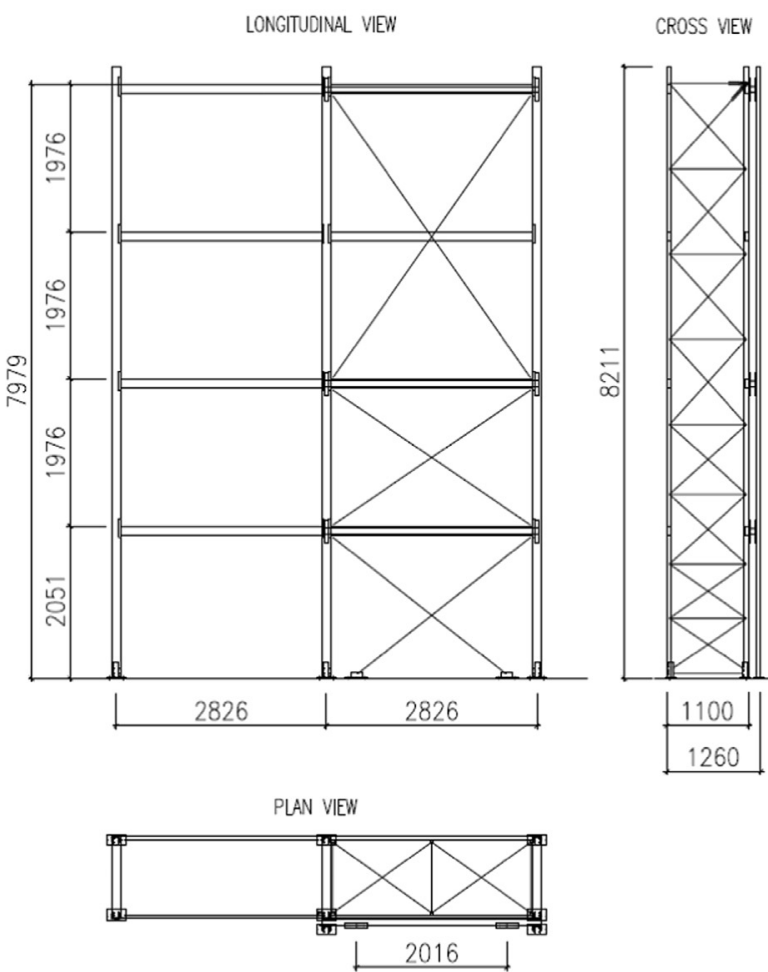

b.

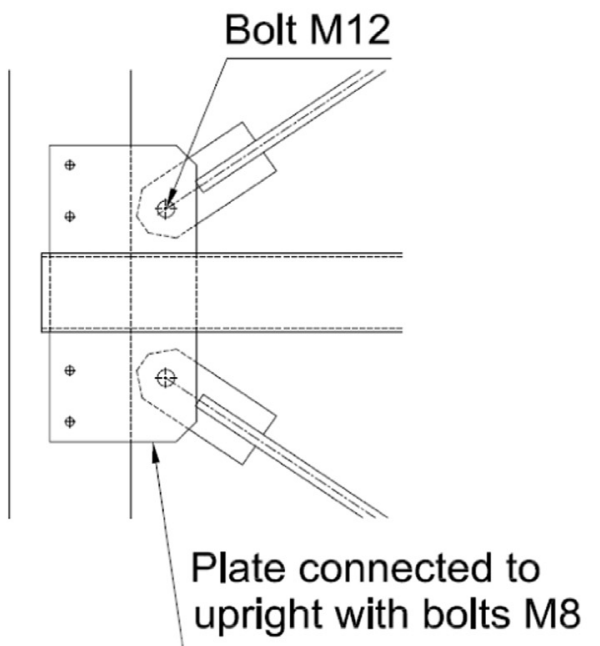

C.

Fig. 5. Specimen IPA2: test layout (a), specimen dimensions (b) and detail of spine bracing connection (c).

Spine bracings are placed in the rear plane of the rack, which makes it stiffer than the front plane. For an efficient distribution of the lateral seismic forces, horizontal bracings are also used to connect upright columns, transferring the seismic actions from the unbraced vertical plane of upright to the braced vertical plane (Fig. 3 ). In this way, torsional effects caused by the global eccen-tricity are minimized [3].

The design of storage racks is not a straight-forward task because of their peculiar structural forms, and difficulties predicting their structural behaviour (both at global and local levels), and becomes even more complicated when storage racks are exposed to horizontal forces in seismic areas. Collapse of racks, during a seismic event, not only endanger the life of the employees and consumers (in case of "open to public" storage areas in shopping centers), but also result in a significant economic loss, much larger than the cost of the rack structure. Some examples observed after recent Emilia-Romagna Earthquake (2012) are shown in Fig. 4 [5]. Picture a. shows the situation in a cheese factory where the racks were toppled down due to the absence of floor-connections. This was a very common type of collapse causing a significant economic loss in the area. In general, it is estimated that 633,700 wheels of Parmigiano Reggiano and Grana Padano cheese were damaged by falling off factory racks, with an estimated cost of the damage about $€ 150$ million. In picture b., the collapse of the clad rack ceramic storage warehouse in Sant'Agostino can be seen [6]. Picture c shows the global collapse of a longitudinally-braced rack 


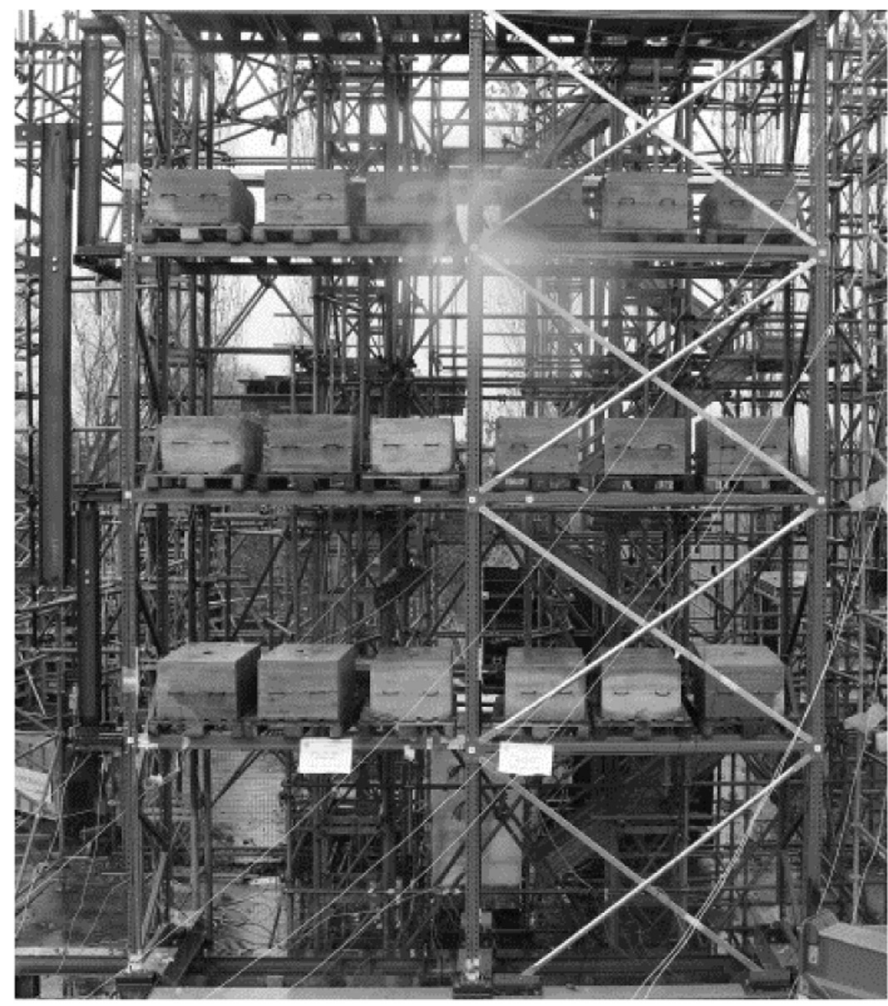

a.

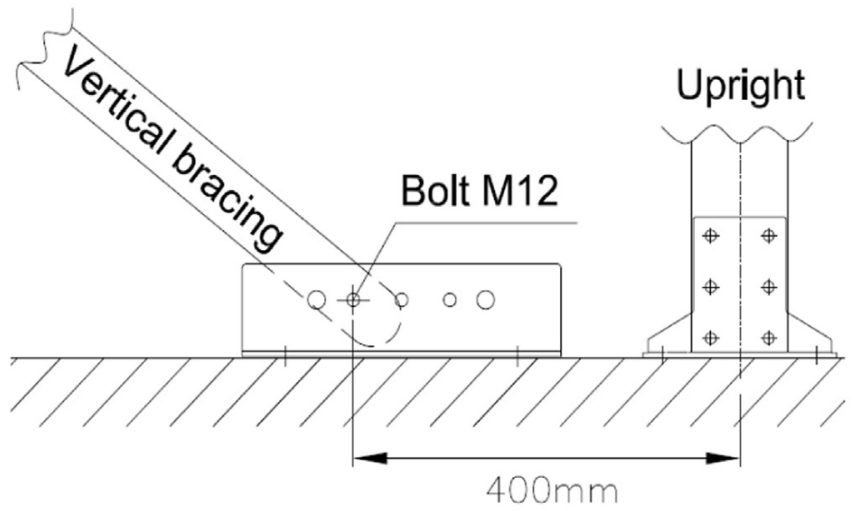

LONGIIUDINAL VIEW
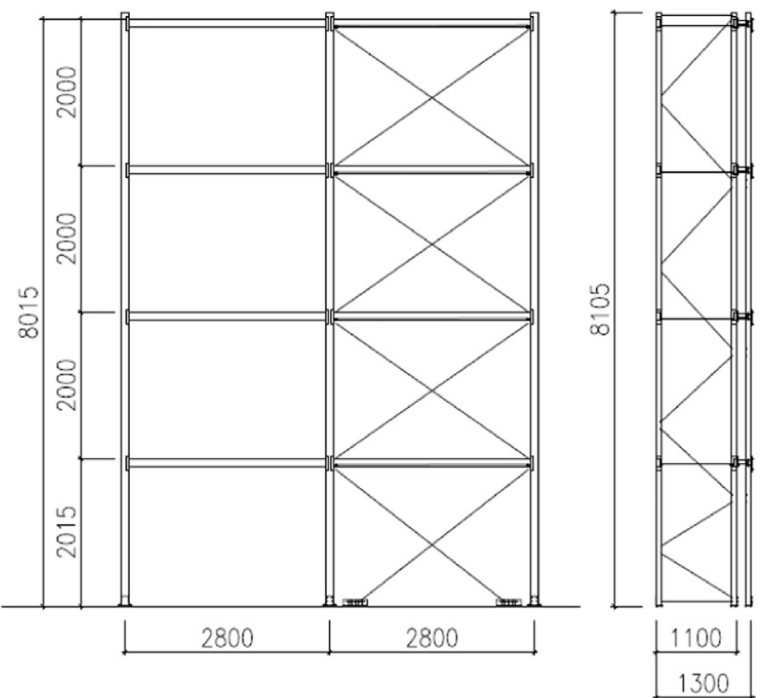

PLAN VIEW

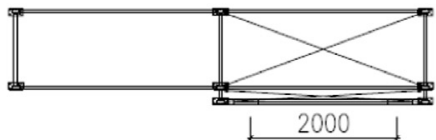

b.

C.

Fig. 6. Specimen IPB2: test layout (a), specimen dimensions (b) and detail of bracing connection to the ground (c).

under the same earthquake. To avoid these social and economic consequences, significant attention should be paid in the design and construction of storage racks located in seismic areas.

Seismic design of steel storage pallet racks is performed with an approach based upon the design philosophy of EN 1998-1 [7]. Seismic action is described by a design spectrum derived from the elastic spectrum by scaling it down with the behaviour factor q, which accounts for the ductility and damping of the racking structure. The reference values of behaviour factor $\mathrm{q}$ for racks are given in accordance with their structural type, i.e. unbraced or braced racks. In unbraced racks (moment-resisting type), horizontal seismic forces are resisted by the flexural behaviour of members and connections. Dissipative zones are mainly located in beam-to-upright connections and in column bases, and the earthquake energy is dissipated by means of cyclic bending. On the other hand, in braced racks, horizontal seismic forces are resisted by the members subject to axial forces. In this case, dissipative zones are mainly located in the tension diagonals. Estimation of behaviour factors for racking systems may not be possible applying the same procedures of common civil engineering structures (e.g. steel, or reinforced concrete buildings), and usually requires experimental studies both at local and global levels.

Most of the experimental studies performed on this topic are mainly limited to characterization of the cold formed rack components and joints at local level (e.g beam-column and base plate connections, compression and tension tests on structural elements) [8-14]. Conclusions of these component-based studies indicate that the response of storage rack systems in their down-aisle direction is significantly influenced by the perforations in the upright profiles, and nonlinear rotational behaviour of beam-toupright and floor connections. However, the combinations of these various ductility resources have not been evaluated well, and the 


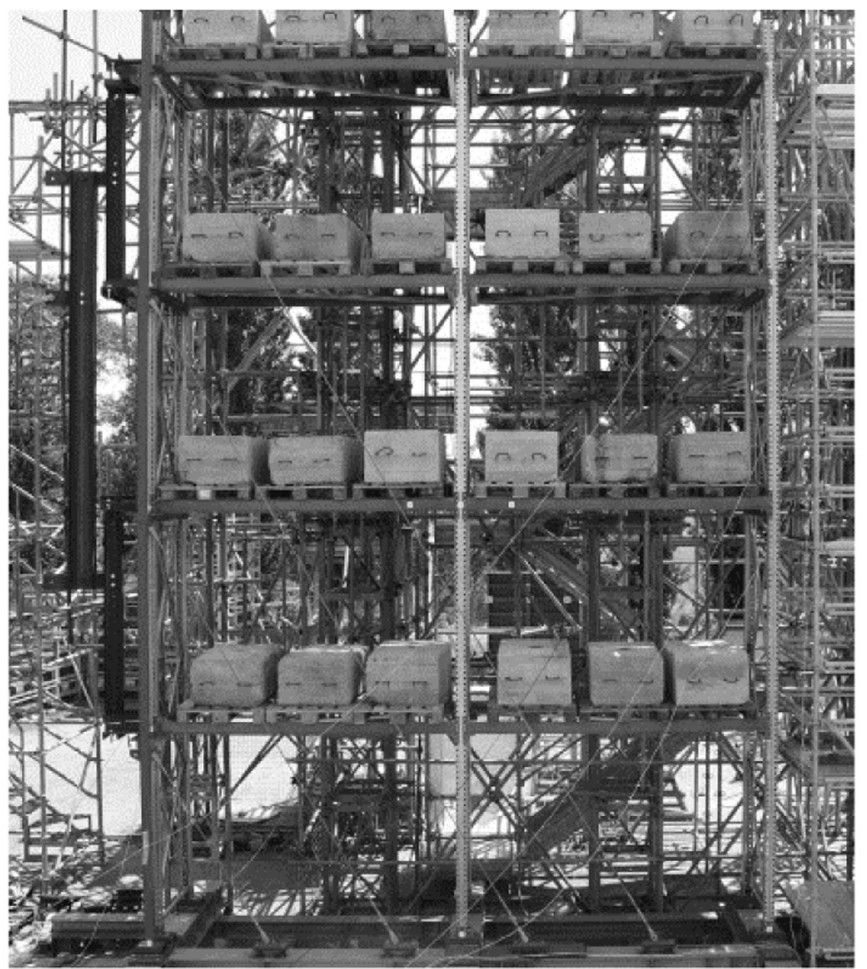

a.

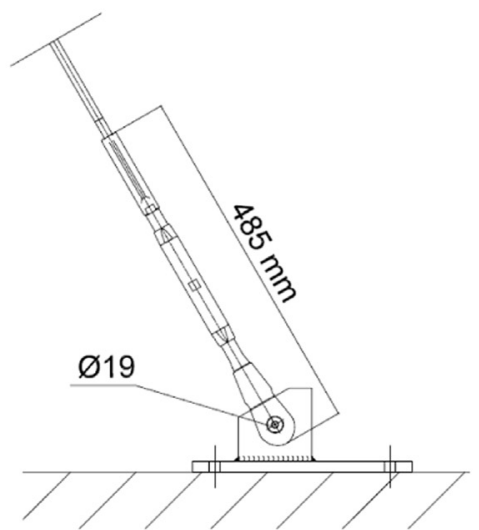

c.
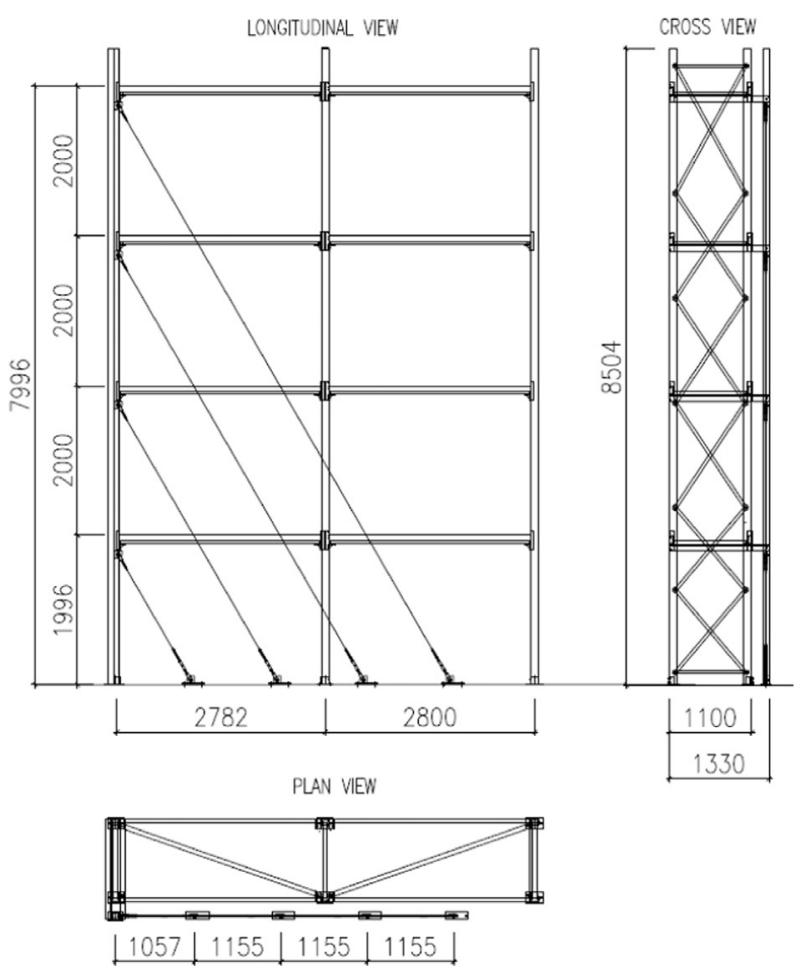

b.

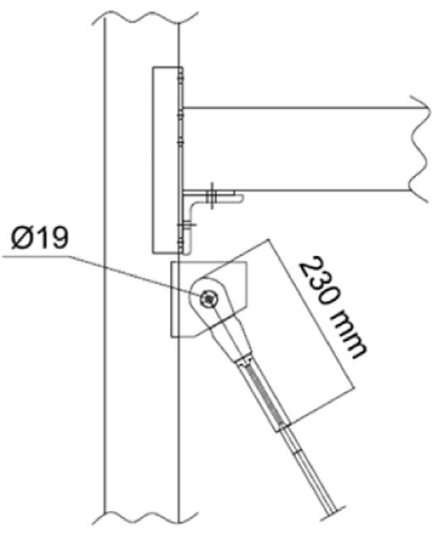

d.

Fig. 7. Specimen IPC2: test layout (a), specimen dimensions (b), detail of bracing connection to the ground (c) and to the spine bracing upright (d).

number of full scale tests with spine bracings in the literature is far from being sufficient to characterize these commonly used racking typologies. This paper provides a significant insight to this aspect, presenting the global behaviour of real-scale braced storage racks under horizontal loading, and quantifying global ductility capacities of very commonly adopted racks with several bracing configurations.

Full scale experiments performed previously only gave limited indications, for a small number of rack configurations, mostly unbraced. The first available results of full scale testing, and analytical investigations on the seismic response of storage racks were published in the mid-1970s by John A. Blume \& Associates [15]. Between 1979 and 1981, cantilever tests, portal tests, quasi-static tests of storage rack systems, dynamic tests (Krawinkler et al. [16]), shake-table tests, and merchandise tests (Chen et al. [17]) were performed. Filiatrault [18] tested five different back-to-back pallet racks loaded with real merchandise on a uniaxial shake-table under a single component, scaled at various amplitudes, under the ground motion recorded at Canoga Park during the 1994 Northridge earthquake. Three of the tests were performed in the crossaisle direction, while the two other tests were performed in the down-aisle direction. The tests performed by Filiatrault et al. [19] on a shake-table indicated that the rotational stiffness of beam-toupright connections is the major factor influencing the down-aisle response of pallet racks under seismic actions. Gilbert et al. [20] performed full scale tests on a complete drive-in rack system, in loaded and empty conditions. They presented the load transfer mechanism in the rack, and its relative stiffness under various horizontal loading conditions.

At European level, shake-table tests on full-scale steel storage pallet racks (both braced and unbraced configurations) loaded by concrete blocks simulating merchandise have been performed within the EC-sponsored ECOLEADER program [21], limited only to two manufacturers' rack typologies. SEISRACKS1 project [21-24] mainly contributed to the definition of coefficients accounting for sliding and energy dissipation in the stored merchandizes, 


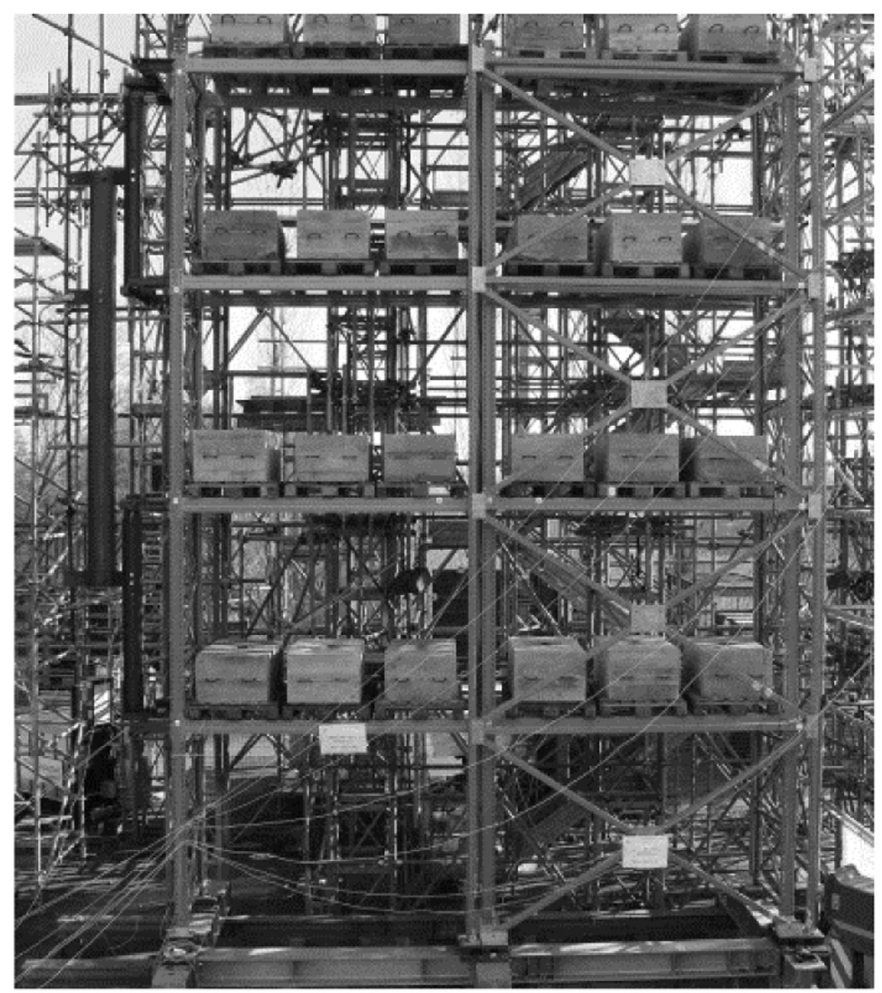

a.

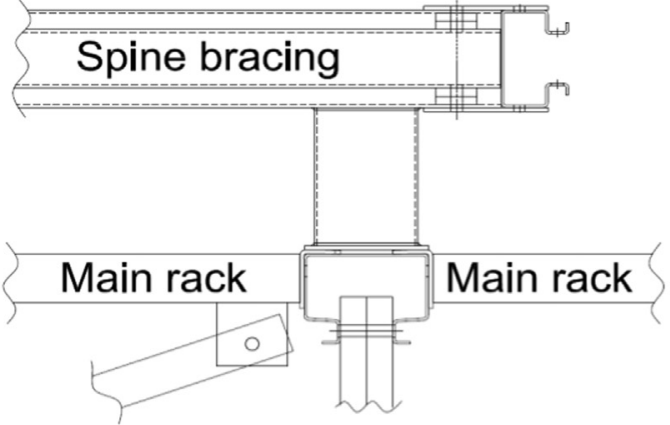

C.

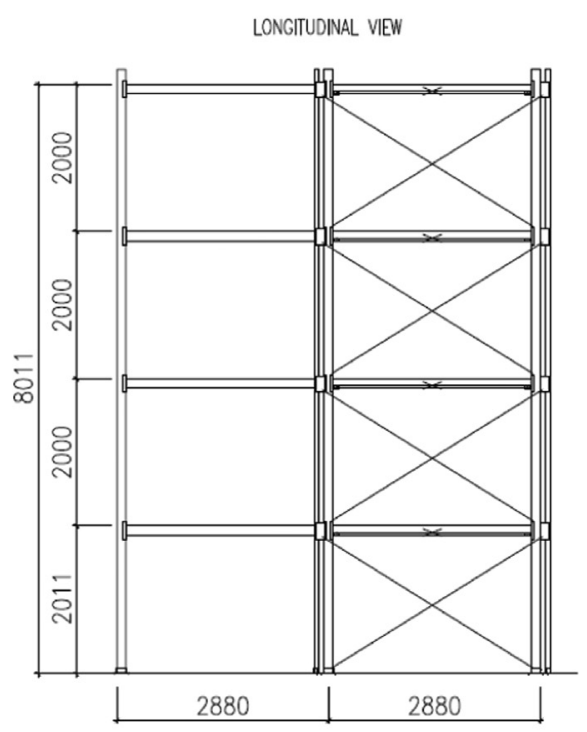

CROSS VIEW
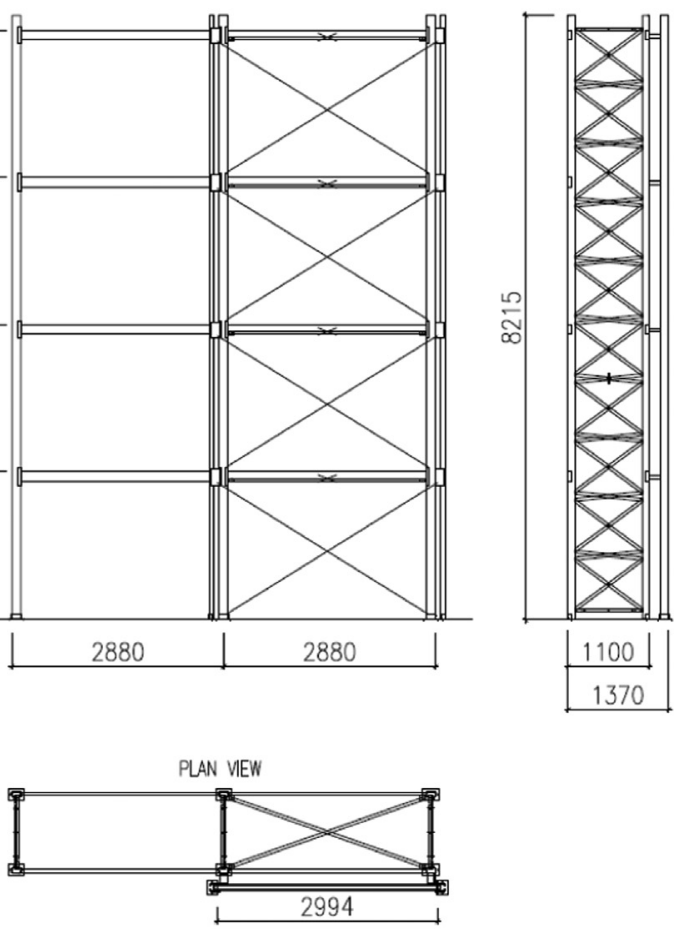

b.

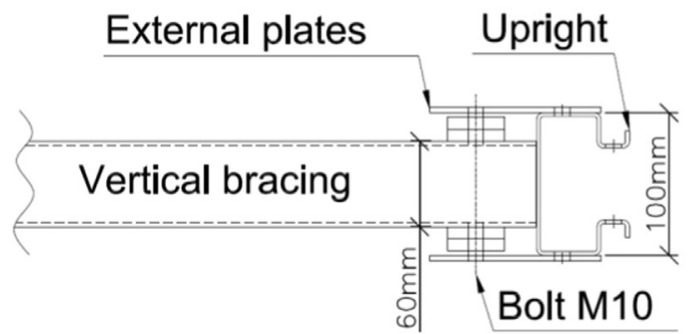

d.

Fig. 8. Specimen IPD2: Test layout (a), Specimen dimensions (b), details of rack to spine bracing connection (c) and spine bracing connection (d).

methods of analysis and ways to account for second order effects, and description of non-dissipative and dissipative design philosophy with associated values of behaviour factors. Despite the satisfactory results achieved from a series of tests on the static and dynamic properties of unbraced steel storage racking systems, many questions remained open regarding ductility and energy dissipation capacity (and consequent q-factors) of several rack configurations widely adopted in practice.

In order to increase the knowledge on the global structural behaviour and ductility of storage racks, a full scale testing program has been carried out within the research project "Seismic Behaviour of Steel Storage Pallet Racking Systems 2" (SEISRACKS2) [24-27], thanks to a financial support of EU Research Fund for Coal and Steel (RFCS). Tests have been performed on braced and unbraced pallet racks provided by different industrial partners of the project. Results of the tests performed on unbraced racks have been presented in a companion paper [28].

This paper presents the results of tests performed on specimens designed with different bracing configurations and design approaches, in terms of global capacity curve, and discusses the key factors affecting the global horizontal response of braced racks. Moreover, authors quantify the global ductility of specimens, providing their behaviour factors $(q)$, in comparison with the design values. Finally, the paper highlights the vulnerability of braced racks to connection failures, and provides design indications for a more ductile rack design with spine bracings.

\section{Experimental setup and test specimens}

To assess global seismic response of the braced racks in down aisle direction, six full scale test specimens have been designed with different cold formed profiles, and identified as IPA2, IPB2, IPC2, IPD2, IPE2 and IPF2. Different bracing configurations have been designed varying element types, connection details and design approach. Each test specimen with its own global dimensions, cross-section geometry of its principal elements and spine bracing connection details is shown from Fig. 5 to Fig. 11. 


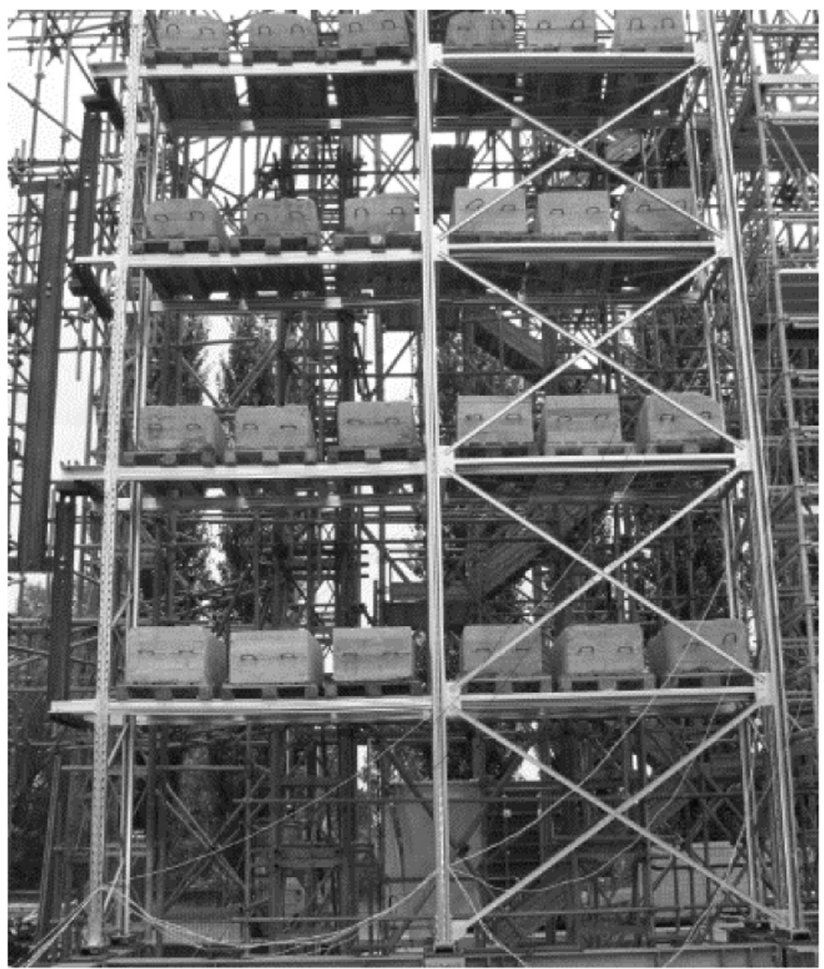

a.

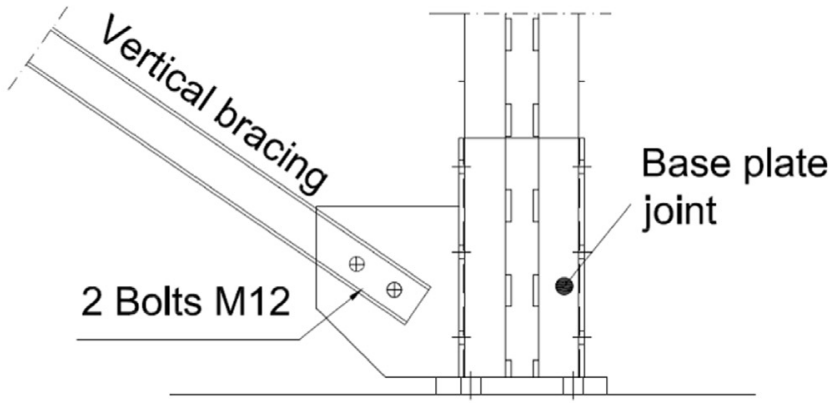

C.

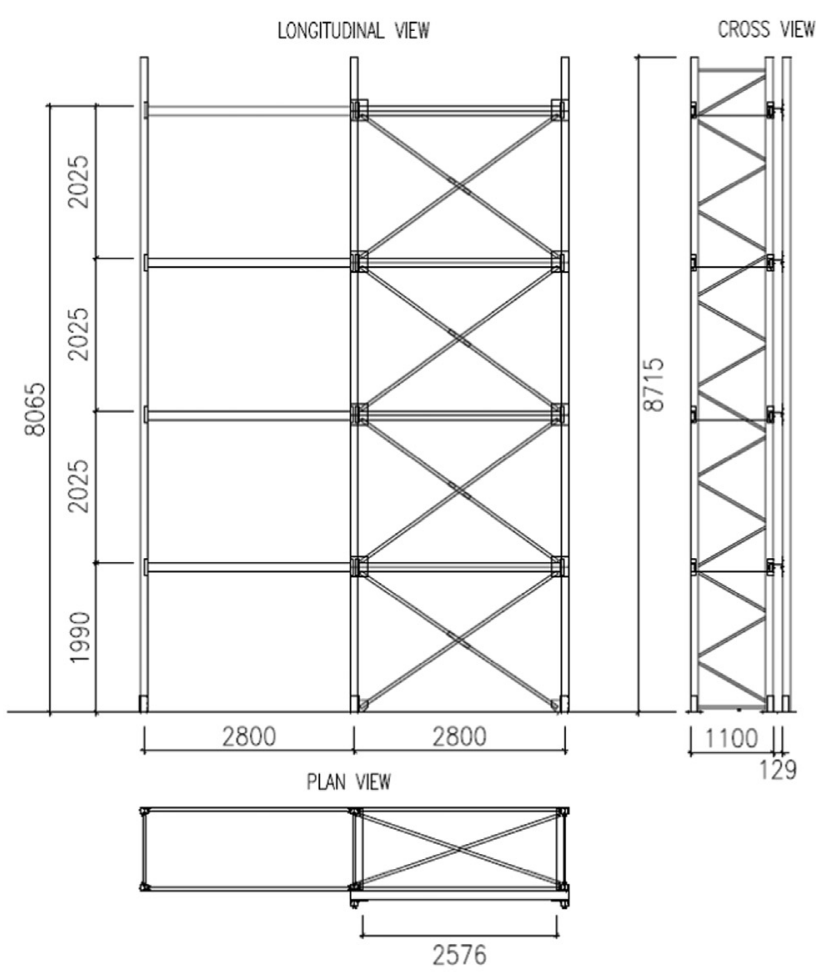

b.

Fig. 9. Specimen IPE2: test layout (a), specimen dimensions (b), detail of spine bracing connection (c).

The cross section characteristics of the upright and beam profiles are presented in Tables 1 and 2 in terms of the ratio between the second moments of area $\left(\mathrm{I}_{\mathrm{y}} / \mathrm{I}_{\mathrm{z}}\right)$, the section moduli $\left(\mathrm{W}_{\mathrm{y}} / \mathrm{W}_{\mathrm{z}}\right)$

and radii of gyration $\left(\rho_{y} / \rho_{z}\right)$, as well as, in case of upright section, the ratio $y_{0} / d$, i.e. the distance between the shear center and the centroid $\left(\mathrm{y}_{0}\right)$ over the distance between the centroid and the web (d). Moreover, the yielding load $\left(\mathrm{A}^{*} \mathrm{f}_{\mathrm{y}}\right)$ and the first yielding (elastic) moment $\left(\mathrm{W}_{\mathrm{y}}{ }^{*} \mathrm{f}_{\mathrm{y}}\right)$ of the gross cross-section are reported in

the same table. Non-dimensional $\alpha, \beta, \gamma, \Omega$, and $\Delta$ parameters have been indicated in Fig. 11.

The geometrical characteristics of the specimens have been defined considering the common rack configurations on the market, and meeting the dimensional limits of the testing facility, which corresponded to the real practice in terms of the number and position of beam levels, weight and dimensions of the unit loads. Therefore, all test specimens are composed of four loaded levels of $2 \mathrm{~m}$ height, one braced upright frame of $1.1 \mathrm{~m}$ width, and two bays of $2.7 \mathrm{~m}$ length. One of the two bays is braced both vertically and horizontally. Slight differences in the precise frame dimensions shown in Table 3 are due to the proprietary component arrangements of each rack producer, which are small enough to be disregarded. Vertical bay loading of the specimens is provided by concrete blocks of $8 \mathrm{kN}$ loaded on wooden pallets, which is an average value for the merchandise used commonly in practice $[29,30,34]$. Three loaded pallets are placed on each bay of the rack specimens to simulate the fully-loaded service condition.

The specimens have been designed by the 5 industrial rack producers according to their daily practice using the design parameters recommended by European Federation of Materials Handling (FEM) standards [3,31-33], and EN 15512 [35]. The design parameters are summarized in Table 4.

Three different approaches have been used in the design of spine bracings of various specimens:

i) Minimizing the eccentricities and applying basic rules of capacity design for the hierarchy of the resistances (IPA2, IPE2, IPF2), so that the capability of parts of the structure to resist earthquake actions through inelastic behaviour is taken into account. Dissipative zones are located in the spine bracing elements, and the rest of the structure has been provided 


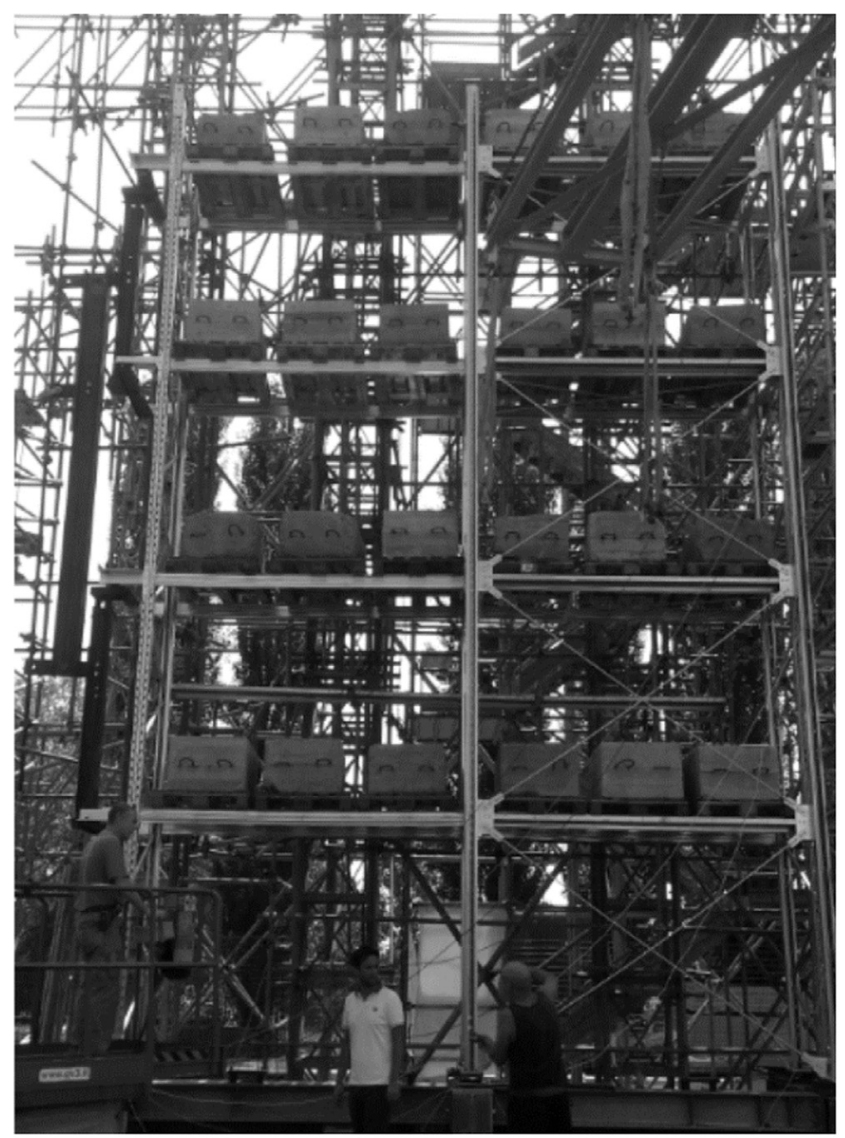

a.

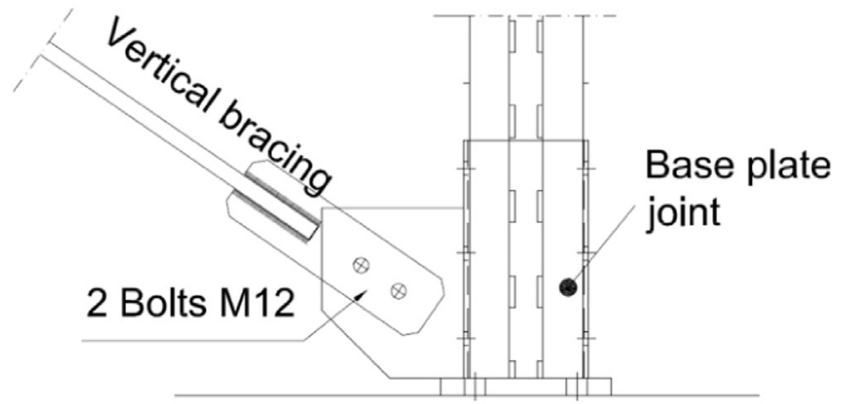

C.

Fig. 10. Specimen IPF2: test layout (a), specimen dimensions (b) and detail of spine bracing connection (c).

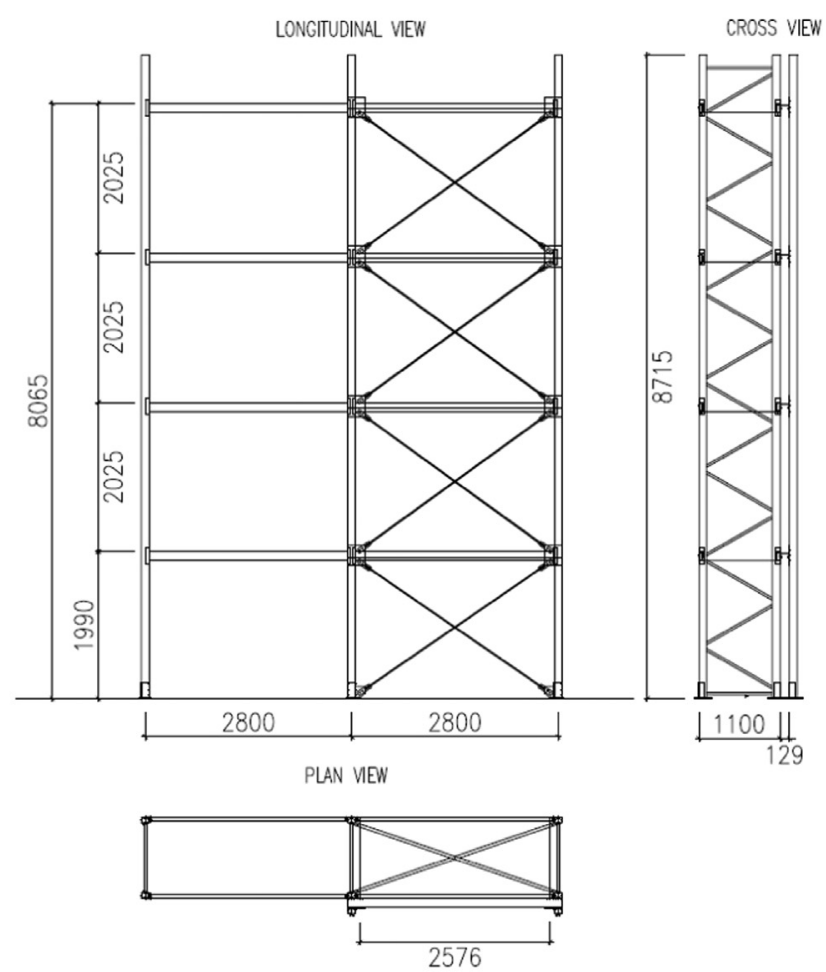

b.

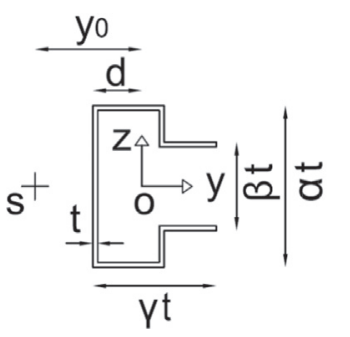

a. Upright cross-sections geometry

b. Pallet beam cross-section geometry

Fig. 11. Cross section and shape parameters of the rack specimens. a. Upright crosssections geometry. b. Pallet beam cross-section geometry.
Table 1

Key geometric parameters of the upright cross-section.

\begin{tabular}{lllllll}
\hline & IPA2 & IPB2 & IPC2 & IPD2 & IPE2 & IPF2 \\
\hline $\boldsymbol{\alpha}$ & 60 & 50 & 40 & 48 & 40 & 40 \\
$\boldsymbol{\beta}$ & 35.5 & 25.5 & 24.4 & 20.2 & 12.4 & 12.4 \\
$\boldsymbol{\gamma}$ & 30 & 38.75 & 40 & 37 & 42 & 42 \\
$\mathbf{A}^{*} \mathbf{f y}[\mathbf{k N}]$ & 283 & 190 & 275 & 348 & 325 & 325 \\
$\mathbf{W y} \mathbf{f y}[\mathbf{k N m}]$ & 9.42 & 5.08 & 8.51 & 11.26 & 8.88 & 8.88 \\
$\mathbf{I y / \mathbf { I z }}$ & 5.15 & 2.66 & 1.37 & 1.89 & 1.10 & 1.10 \\
$\boldsymbol{\rho} \mathbf{y} / \mathbf{\rho z}$ & 2.27 & 1.60 & 1.17 & 1.36 & 1.05 & 1.05 \\
$\mathbf{W y} / \mathbf{W z}, \mathbf{l e f t}$ & 2.02 & 1.04 & 1.11 & 1.24 & 0.97 & 0.97 \\
$\mathbf{W y} / \mathbf{W z}, \mathbf{r i g h t}$ & 3.13 & 2.56 & 1.64 & 1.67 & 1.34 & 1.34 \\
$\mathbf{y 0 / d}$ & 1.82 & 2.30 & 2.22 & 2.12 & 2.07 & 2.07 \\
\hline
\end{tabular}


sufficient over-strength to remain elastic under horizontal loading

ii) Without special attention to the detailing, using the design rules for the strength of the connections (IPB2, IPD2);

iii) Imposing spine bracings an over-strength (IPC2).

Since the case studies represent racks for common storage applications in standard warehouse conditions, a design life of 30 years is considered. Importance factor is taken as $\gamma_{I}=0.85$, which corresponds to the second importance class. Behaviour factors

(q) equal to 1.5 has been used in the design.

In Table 5, bracing configuration of each specimen in elevation and plan has been shown. Two types of spine bracing schemes have been identified. The first one is composed of $\mathrm{X}$ bracings with extra uprights and extra horizontal elements; diagonals either working only in tension made of steel plates or rounded bars (IPA2), or working both in tension and compression made of tubes (IPB2, IPD2) or channels (IPE2, IPF2). The second bracing scheme is made by cables with turnbuckle and post element (IPC2).

Horizontal bracing systems have been diversified in order to find the best configuration to reduce global torsion of specimens. As shown in Fig. 12, four configurations have been adopted in plan:

a. Connection of the spine bracing to the rack is provided by a rigid frame, made of a U-shaped welded profile (IPD2);

b. Extra transversal elements are installed, connecting the uprights in the direction of the upright frame. Connection of the

Table 2

Key geometric parameters of the pallet beam cross-section.

\begin{tabular}{lllllll}
\hline & IPA2 & IPB2 & IPC2 & IPD2 & IPE2 & IPF2 \\
\hline $\mathbf{\Omega}$ & 30 & 26.67 & 33.33 & 28.57 & 40 & 40 \\
$\boldsymbol{\Delta}$ & 80 & 73.33 & 73.33 & 74.29 & 96 & 96 \\
$\mathbf{A}^{*} \mathbf{f y}[\mathbf{k N}]$ & 228 & 165 & 229 & 192 & 215 & 215 \\
$\mathbf{W y}^{*} \mathbf{f y}[\mathbf{k N m}]$ & 7.99 & 5.25 & 7.72 & 7.35 & 7.35 & 7.35 \\
$\mathbf{l y} / \mathbf{l z}$ & 6.22 & 8.83 & 4.73 & 6.20 & 6.77 & 6.77 \\
$\mathbf{\rho y} / \mathbf{\rho z}$ & 2.49 & 2.97 & 2.17 & 2.50 & 2.15 & 2.15 \\
$\mathbf{W y} / \mathbf{W z}$ & 2.33 & 4.45 & 2.13 & 2.38 & 1.61 & 1.61 \\
\hline
\end{tabular}

spine bracing to the rack is provided by a rigid frame (IPA2, IPE2, IPF2);

c. Connection of the horizontal bracing to the spine bracing is made by two transversal elements (angle shape) fixed under the pallet beams (IPC2);

$\mathrm{d}$. Connection of the spine bracing to the rack is made by spacers and the horizontal stiffness is provided by tension only bracing. (IPB2).

Proprietary semi-rigid beam-end and base plate joints have been used by each partner in the structural design, whose response properties were characterized by experimental assessment according to the EN15512 [35]. Experimental stiffness curves of the floor and upright-beam connections, normalized, respectively, by design moment resistance $\left(\mathrm{M}_{\mathrm{d}}\right)$ of upright and pallet beam, are shown in Fig. 13.

Major horizontal stability of the racks is provided by the spine bracings connected to their rear plane. This is the only possible bracing location for storage racks, which allows pallet loading from one of the two aisles. The torsional effects created by this asymmetric configuration is tried to be minimized by horizontal bracings, which transfer the horizontal actions from one plane to the other.

In order to characterize the global behaviour in down-aisle direction, horizontal push-over static loading has been applied within the relevant longitudinal natural mode of the test specimens, which follows, in terms of the size of mass participation, the natural modes in down-aisle direction (Table 6). An inverted

Table 5

Spine and horizontal bracing configurations.

\begin{tabular}{llll}
\hline $\begin{array}{l}\text { Horizontal bracing } \\
\text { configuration }\end{array}$ & Cables & \multicolumn{1}{l}{ X Bracings } \\
\cline { 3 - 4 } & & Tension only & Tension/Compression \\
\hline (a) & & & IPD2 \\
(b) & & IPA2, IPF2 & IPE2 \\
(c) & IPC2 & & \\
(d) & & IPB2 & \\
\hline
\end{tabular}

Table 3

Geometrical characteristics of rack specimens.

\begin{tabular}{|c|c|c|c|c|c|c|}
\hline & IPA2 & IPB2 & IPC2 & IPD2 & IPE2 & IPF2 \\
\hline Down-aisle configuration & X-bracing & X-bracing & V-bracing & $\mathrm{X}$-bracing & X-bracing & X-bracing \\
\hline Cross-aisle configuration & $\mathrm{X}$-bracing & D-bracing & $\mathrm{X}$-bracing & $\mathrm{X}$-bracing & D-bracing & D-bracing \\
\hline Frame depth (mm) & 1100 & 1100 & 1100 & 1100 & 1100 & 1100 \\
\hline Bay length (net span) (mm) & 2706 & 2700 & 2700 & 2700 & 2700 & 2700 \\
\hline Rack height (mm) & 7979 & 8015 & 7996 & 8011 & 8065 & 8065 \\
\hline First load level (mm) & 2051 & 2015 & 1996 & 2011 & 1990 & 1990 \\
\hline Upper floor heights (mm) & 1976 & 2000 & 2000 & 2000 & 2025 & 2025 \\
\hline
\end{tabular}

Table 4

Parameters used in the design of tests specimens.

\begin{tabular}{|c|c|c|c|c|c|c|}
\hline Design Earthquake Intensity & $\begin{array}{l}\text { IPA2 } \\
\text { High seismicity }\end{array}$ & $\begin{array}{l}\text { IPB2 } \\
\text { Moderate seismicity }\end{array}$ & $\begin{array}{l}\text { IPC2 } \\
\text { High seismicity }\end{array}$ & $\begin{array}{l}\text { IPD2 } \\
\text { Moderate seismicity }\end{array}$ & $\begin{array}{l}\text { IPE2 } \\
\text { High seismicity }\end{array}$ & $\begin{array}{l}\text { IPF2 } \\
\text { High seismicity }\end{array}$ \\
\hline Pallet mass & \multicolumn{6}{|l|}{$800 \mathrm{~kg}$} \\
\hline Soil Type & \multicolumn{6}{|l|}{ C } \\
\hline Importance Class & \multicolumn{6}{|c|}{ II } \\
\hline Design Life & \multicolumn{6}{|c|}{30 years $\rightarrow \gamma 1=0.84$ (normal use of the racks) } \\
\hline ED3 & \multicolumn{6}{|l|}{0.67} \\
\hline q-design & \multicolumn{6}{|l|}{1.5} \\
\hline
\end{tabular}




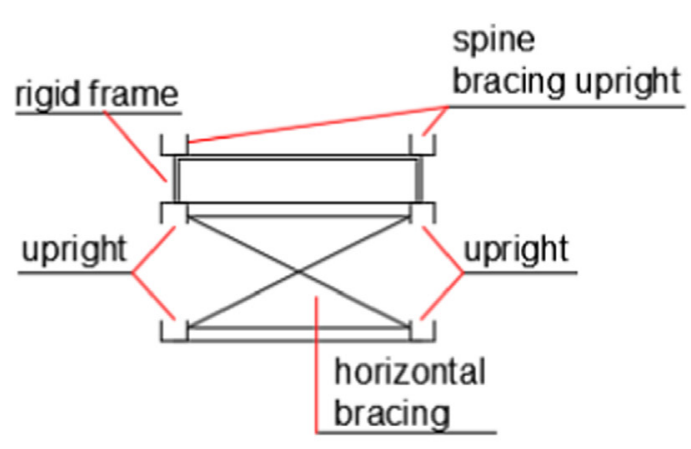

a.

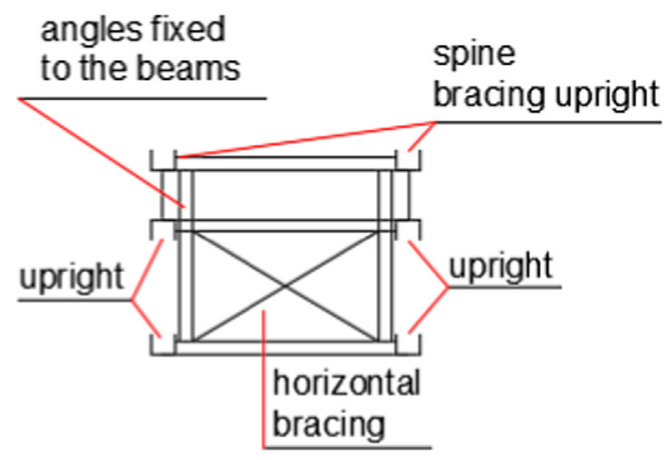

C.

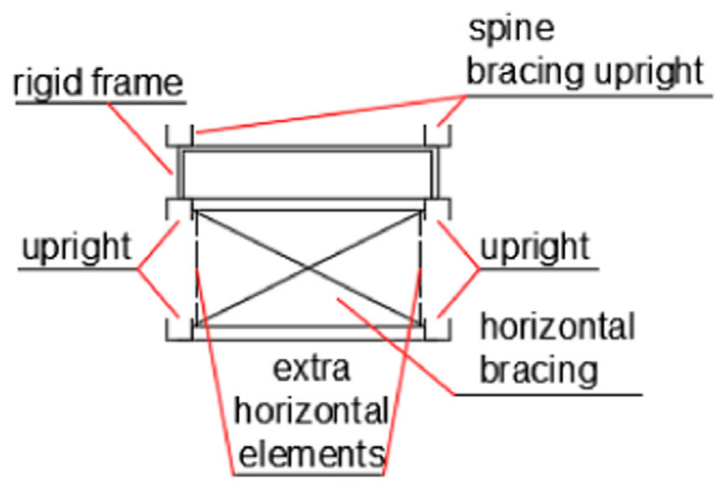

b.

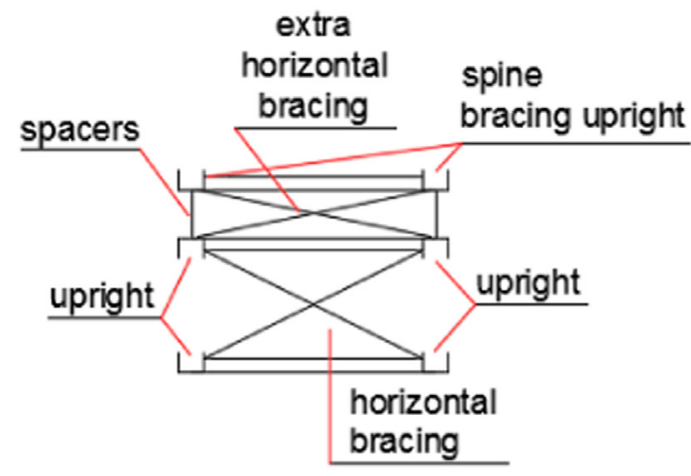

d.

Fig. 12. Horizontal bracing schemes.

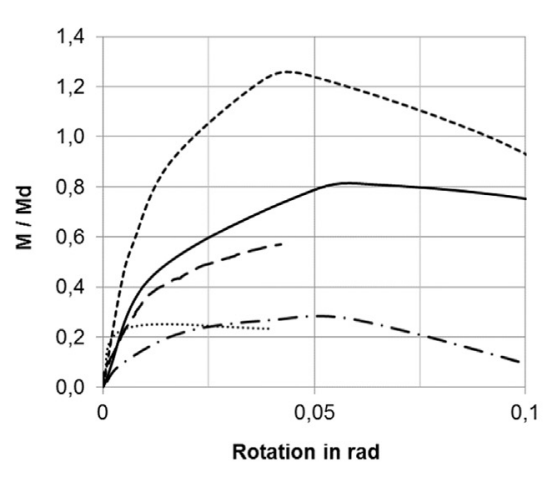

(a)

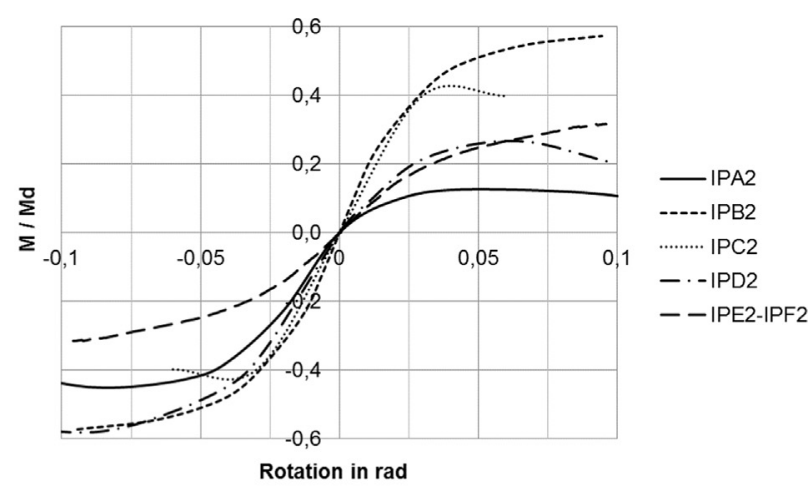

(b)

Fig. 13. Flexural stiffness curves of floor connections (a) and beam-to-upright connectors (b).

triangular pattern has been applied (Fig. 14) so that the level loads are proportional to the dynamic inertia of each level, which is a typical force-controlled loading condition [36,37].

To investigate the three dimensional behaviour of the racks, the displacements of relevant nodes are monitored and recorded. For this purpose, twelve potentiometric displacement transducers were used. Eight transducers were placed, two for each level of the rack, in order to monitor the longitudinal backside and front side down-aisle direction displacements, while 4 transducers were placed backside at the second and fourth floor on the left and right side of the rack, to measure the displacements in cross aisle direction. The general test layout is shown in Fig. 15. Plan view of the transducers are shown in Fig. 16.

During tests, photographic surveys were carried out with the purpose both to have a photographic documentation of the work and to have a back-up information of the deformed shapes of the structure by means of photogrammetric re-analysis [38] (Fig. 17).

\section{Test results}

The test results are presented as global capacity curves, plotted in terms of top displacement values versus total base shear (Fig. 18). After a careful analysis of the different approaches proposed in the literature [39-44] authors proposed the following procedure, in order to evaluate the global yield base shear $\left(\mathrm{F}_{\mathrm{y}}\right)$, and corresponding global yield displacement $\left(\mathrm{d}_{\mathrm{y}}\right)$ values, making reference to ECCS45 [39]: 
Table 6

Numerical modal analysis results of the specimens.

\begin{tabular}{|c|c|c|c|c|}
\hline & Mode & Period [s] & Mass Part. [\%] & Degree of freedom \\
\hline \multirow[t]{4}{*}{ IPA2 } & 1 & 0.90 & 42 & Downaisle \\
\hline & 2 & 0.65 & 28 & Crossaisle \\
\hline & 3 & 0.60 & 63 & Torsional \\
\hline & 4 & 0.40 & 30 & Downaisle \\
\hline \multirow[t]{4}{*}{ IPB2 } & 1 & 0.91 & 34 & Downaisle \\
\hline & 2 & 0.63 & 56 & Crossaisle \\
\hline & 3 & 0.60 & 43 & Torsional \\
\hline & 4 & 0.40 & 39 & Downaisle \\
\hline \multirow[t]{4}{*}{ IPC2 } & 1 & 0.77 & 56 & Downaisle \\
\hline & 2 & 0.69 & 67 & Crossaisle \\
\hline & 3 & 0.54 & 39 & Torsional \\
\hline & 4 & 0.50 & 19 & Downaisle \\
\hline \multirow[t]{4}{*}{ IPD2 } & 1 & 0.87 & 22 & Downaisle \\
\hline & 2 & 0.67 & 49 & Crossaisle \\
\hline & 3 & 0.66 & 40 & Torsional \\
\hline & 4 & 0.32 & 41 & Downaisle \\
\hline \multirow[t]{4}{*}{ IPE2 } & 1 & 0.80 & 36 & Downaisle \\
\hline & 2 & 0.59 & 29 & Torsional \\
\hline & 3 & 0.55 & 42 & Crossaisle \\
\hline & 4 & 0.32 & 36 & Downaisle \\
\hline \multirow[t]{4}{*}{ IPF2 } & 1 & 0.82 & 40 & Downaisle \\
\hline & 2 & 0.60 & 30 & Torsional \\
\hline & 3 & 0.56 & 42 & Crossaisle \\
\hline & 4 & 0.36 & 34 & Downaisle \\
\hline
\end{tabular}

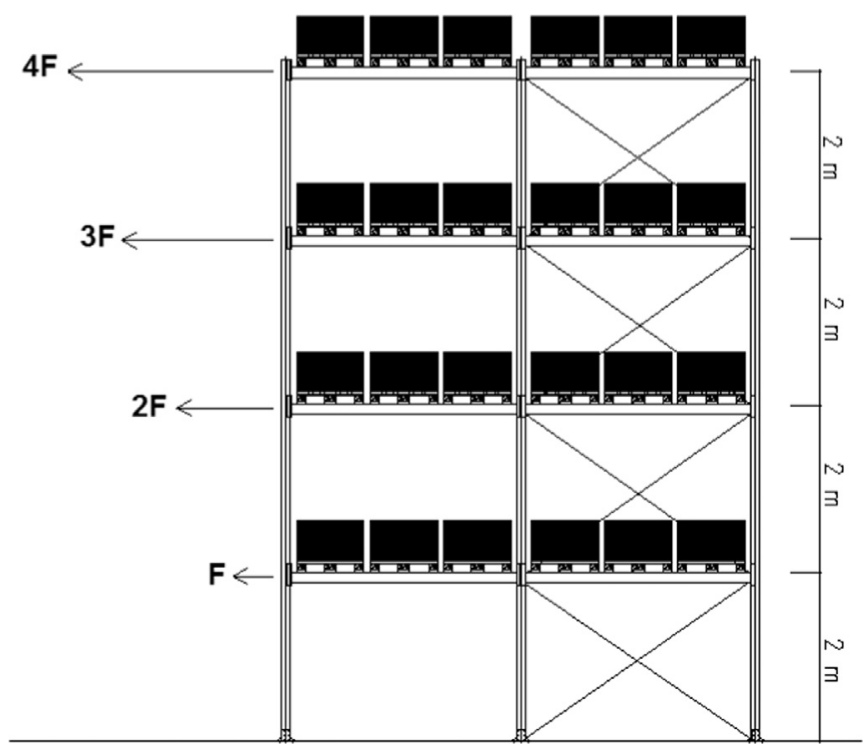

Fig. 14. Loading scheme.

i. Initial stiffness of the curves are approximated by the tangent slope obtained at their origin (Fig. 19);

ii. The global yield base shear $F_{y}$ and the corresponding yield displacement $\mathrm{d}_{\mathrm{y}}$ are deduced by locating the $1 / 10$ of the initial stiffness slope on the global force-deformation curves. The intersection of the two tangents defines the level of $F_{y}$, and the displacement corresponding to the intersection is defined as $\mathrm{d}_{\mathrm{y}}$;

iii. Base shear forces $\left(\mathrm{F}^{*}\right)$ have been normalized on the global yield shear force $\left(\mathrm{F}_{\mathrm{y}}\right)$ :

$\underline{F}$

$=\boldsymbol{F}^{*}$

$\boldsymbol{F}_{\boldsymbol{y}}$ iv. Displacements $\left(\mathrm{d}^{*}\right)$ have been normalized on the yield displacement of the frame $\left(d_{y}\right)$ :

$$
\frac{d}{d_{y}}=d^{*}
$$

IPA2, IPE2 and IPF2 showed a global ductile performance, provided by their significant deformation capacity, thanks to the exploitation of the inelastic resources of the spine bracings, without a sudden local failure in their elements. IPB2 and IPD2 both had local failures before taking advantage of the inelastic resources of the spine bracings. Specimen IPC2 was more resistant than the maximum capacity of testing jack, therefore a failure until the end of the test cannot be observed. However, its pushover curve remained almost linear until the end of test, which means the deformations of rack members mainly were elastic.

From the measurements obtained by the transducers placed in both uprights of the (upright) frame, it is seen that the specimens had a moderate global torsional behaviour, due to the asymmetry of their structural configuration, although it was limited thanks to the horizontal bracings used at each level (Fig. 20). It has been noted that the global torsion was minimum in the case of horizontal bracing configuration (c), where the loads were distributed among both uprights and the spine bracing plane (Table 7). The highest torsion values have been observed in case of horizontal bracing configuration (a), where only the uprights on one side have been connected to the spine bracing plane (Fig. 12).

Although capacity design approach traditionally developed for standard hot rolled steel elements and connections cannot be directly applied to the non-standard and proprietary elements of storage racks, test results confirm that a significant overstrength should be guaranteed for their connections in order to avoid a brittle failure mechanism, such as the shear/ bending of the bolts, and to obtain a global ductile behaviour in the storage racks with spine bracings.

Fig. 5a shows the connection configuration of specimen IPA2, which had a sufficient overstrength, and lead the bracing elements to have large inelastic deformation, finally resulting in a good 


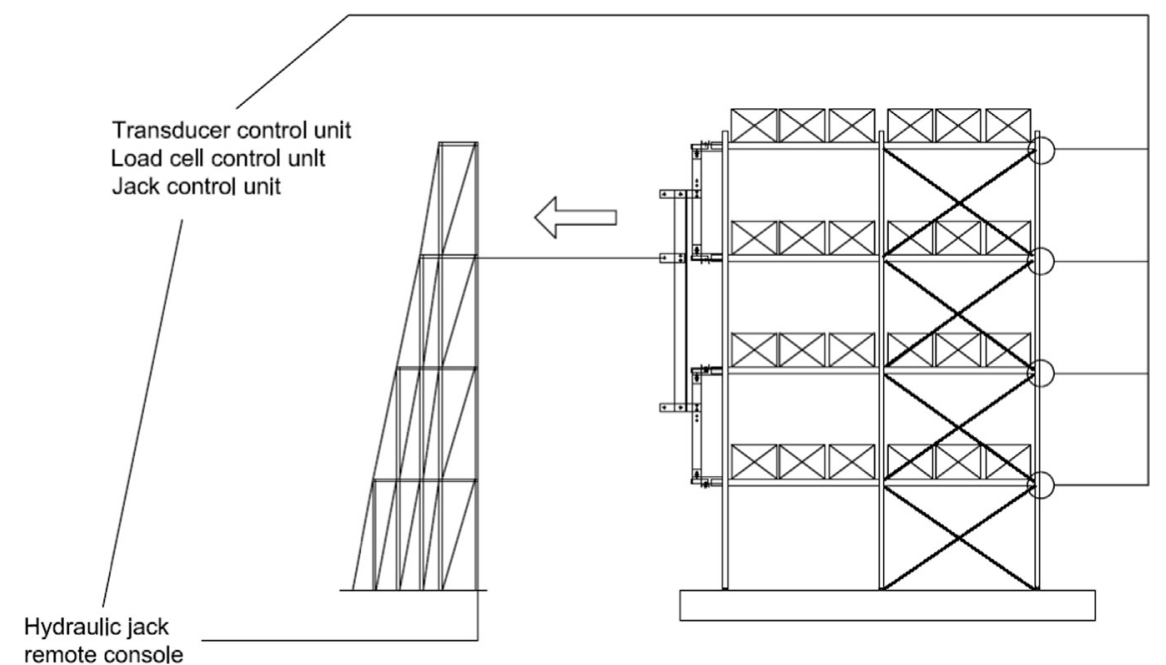

Fig. 15. General test layout.

\section{Transducers in}

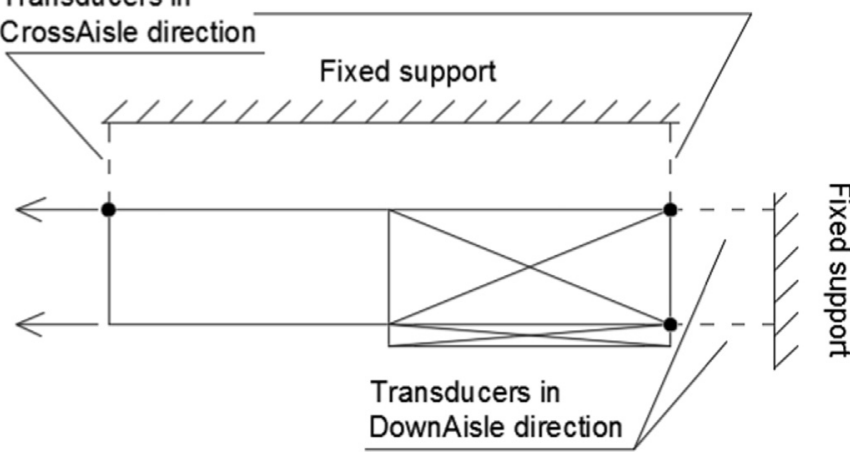

Fig. 16. Plan view of transducers layout. over-strength of connections are guaranteed with simple connection detailing and tension-only bracing elements (Fig. 23).

On the other hand, connection configurations of specimen IPB2 (Fig. 6e) and IPD2 (Fig. 8e and f) do not let the rack specimen exploiting their inelastic capacity, causing sudden connection failures. In particular, specimen IPB2 had a bolt shear failure at the connection of the ground level spine bracing to its base plate (Fig. 24), while specimen IPD2 had a connection failure of the spine bracing at the first level due to high bending deformations concentrated in the bolt and the connecting plates (Fig. 25). Therefore, spine bracings of the storage racks should be designed to impose an over-strength to connections either using relatively weak tensile bracings or by means of robust connections. The eccentricity between the bracing system and the rack should also be minimized in order to avoid intensive torsional effects and nonuniform distribution of forces.

\section{Assessment of behaviour factor (Q)}

The resistance and energy-dissipation capacity of a structure are related to the extent to which its nonlinear response is global ductility of the specimen (Fig. 21). In this case, the test has been stopped when flexural-torsional and distortional buckling of the upright of the spine bracing occurred (Fig. 22).

Similar comments can be made also for the specimens IPC2 (Fig. 7e and f), IPE2 (Fig. 9e), and IPF2 (Fig. 10d), where the

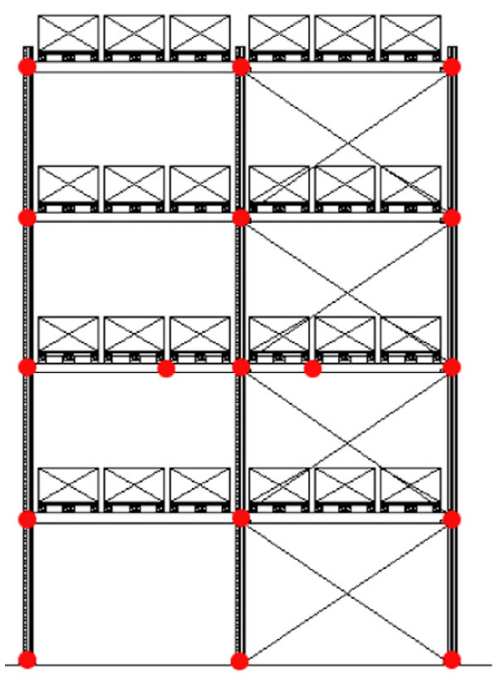

a) Targets disposition

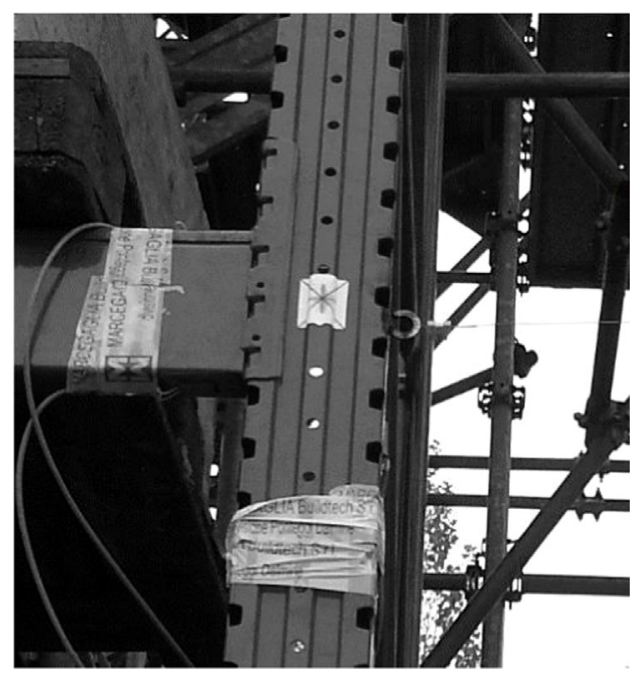

b) Target bonded to a joint

Fig. 17. Photogrammetric monitoring. (a) Targets disposition. (b) Target bonded to a joint. 


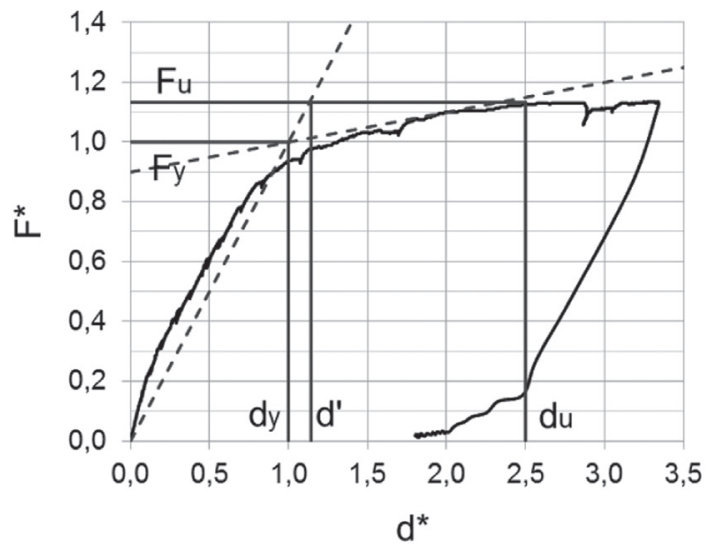

a. IPA2

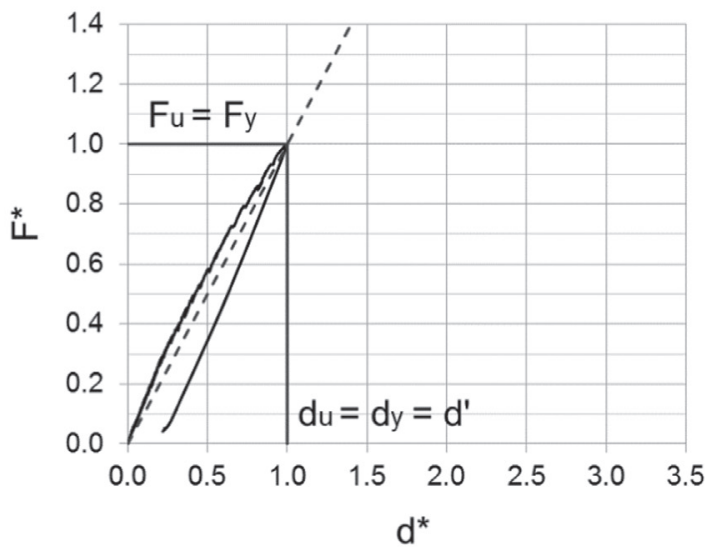

c. IPC2

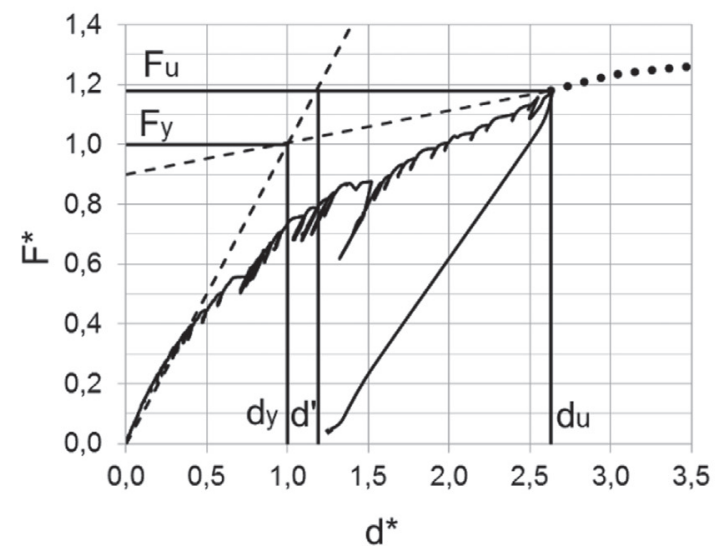

e. IPE2

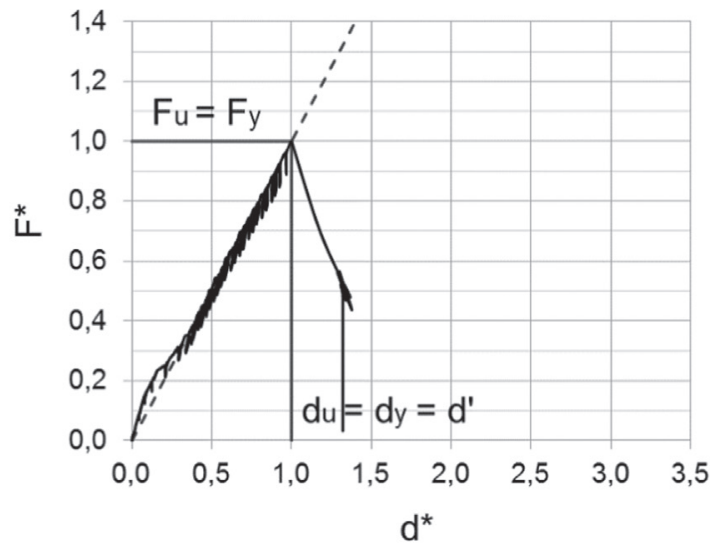

b. IPB2

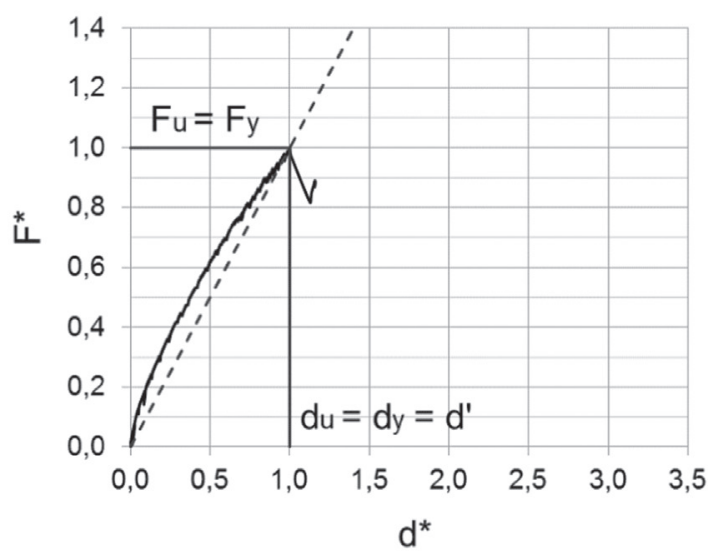

d. IPD2

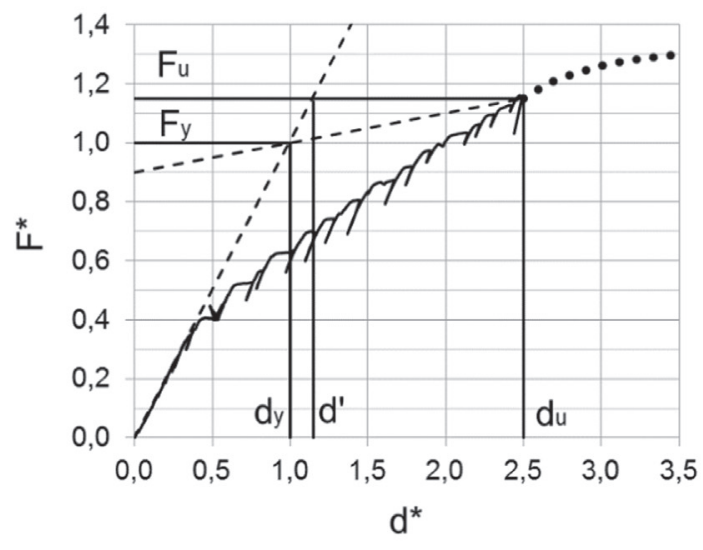

f. IPF2

Fig. 18. Global force-displacement diagrams of tests.

exploited. In operational terms, such balance between resistance and energy-dissipation capacity is characterized by the values of the behaviour factor q. The q-factor is defined as the product of the over-strength and the ductility ratio as shown in the following equations:

$\boldsymbol{\Omega}=\frac{\boldsymbol{F}_{\boldsymbol{u}}}{\boldsymbol{F}_{\boldsymbol{y}}} ; \boldsymbol{q}_{0}=\frac{\boldsymbol{d}_{\boldsymbol{u}}}{\boldsymbol{d}^{\prime}} ; \boldsymbol{q}=\boldsymbol{\Omega} \cdot \mathbf{q}_{0}$ where:

$-\Omega$ is the over-strength factor

- $\mathrm{q}_{0}$ is the ductility ratio

- $F_{y}$ is the global yield base shear

- $\mathrm{F}_{\mathrm{u}}$ is the ultimate load before collapse

$-\mathrm{d}_{\mathrm{u}}$ is the displacement associated to $F_{u}$

- $\mathrm{d}^{\prime}$ is the displacement associated to the intersection between the 


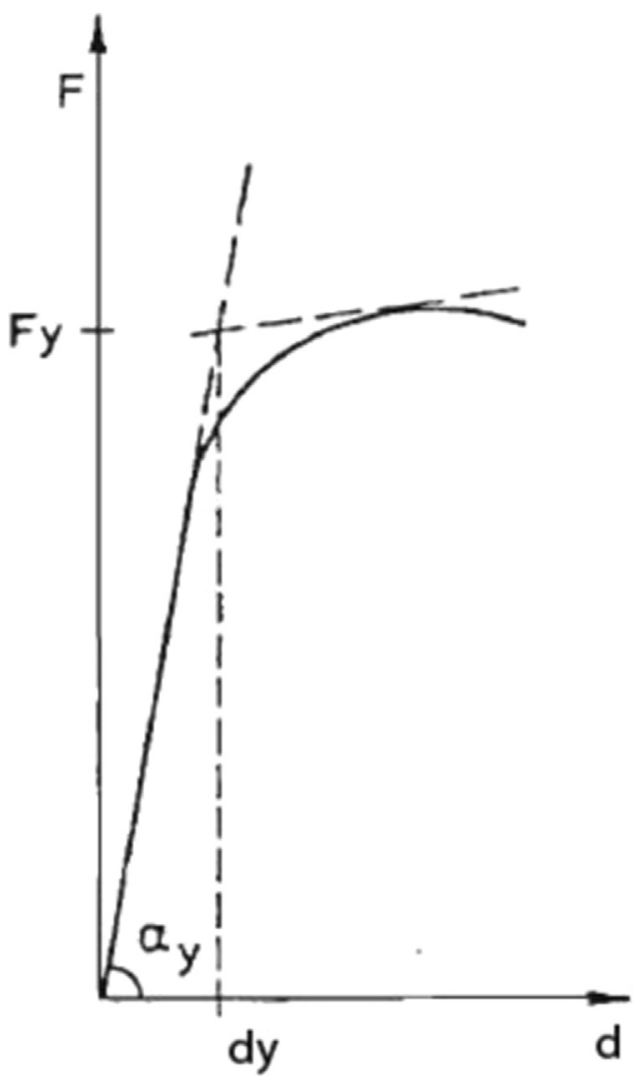

Fig. 19. Definition of yield force by ECCS45 [39].

Table 7

Torsional behaviour of the different specimens.

\begin{tabular}{ll}
\hline Specimen & $\mathbf{d}_{\mathbf{B}} / \mathbf{d}_{\mathbf{A}}$ \\
\hline IPA2 - Configuration (b) & 0.82 \\
IPB2 - Configuration (d) & 0.81 \\
IPC2 - Configuration (c) & 0.89 \\
IPD2 - Configuration (a) & 0.72 \\
IPE2 - Configuration (b) & 0.76 \\
IPF2 - Configuration (b) & 0.69 \\
\hline
\end{tabular}

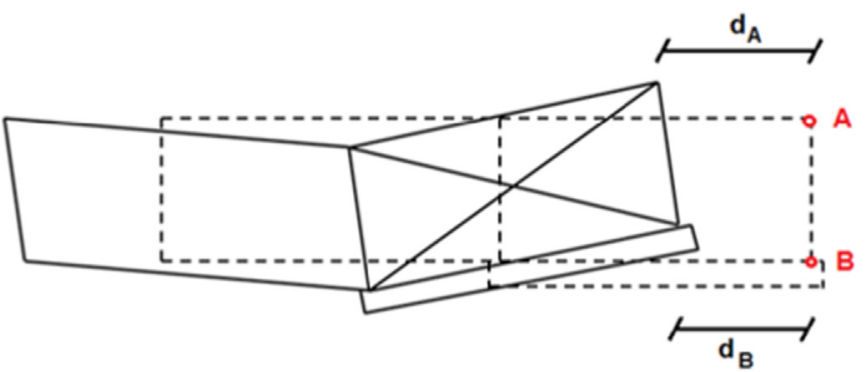

Fig. 20. Torsional behaviour of braced storage rack.

tangent slope and $\mathrm{F}_{\mathrm{u}}$

The values of these parameters are shown for each specimen in Fig. 18. Table 8 presents the q values estimated for each test specimen. For specimens IPE2 and IPF2, tests were stopped before the collapse for safety reasons, therefore the $q$ values of these specimens should be considered as lower bound values.

Global ductility of specimens IPA2, IPE2, IPF2 resulted in moderate q values, showing an appropriate capacity of these racks to dissipate earthquake forces. On the contrary, IPB2 had lower q values as a result of their global brittle behaviour. For specimen IPC2, the test was stopped because of jack's capacity $(100 \mathrm{kN})$, yet design elastic limit of the structure was reached at the end of the test. Although a local failure was not observed during the test of this specimen, at the end of the test, deformations of the structure remained mainly in the elastic phase, therefore $q$ value of this specimen could not have been determined. It should be also noted that the $\mathrm{q}$ values obtained by experimental tests of the latter specimens are lower than the assumed ones in design phase.

It should be also noted that the $q$ values obtained by experimental tests of the latter specimens are lower than the assumed ones in design phase.

Among three design approaches that have been used in the design of spine bracings of various specimens, typology (i) was the only one resulting in a relatively high ductility, with a behaviour factor larger than 2, thus demonstrating that $\mathrm{q}=2$ can be reliably assumed provided that inelastic deformations can develop in diagonals before connection failure. The typology (ii) on the contrary has shown over-strength but very low ductility because of the failure of the connections of the spine bracing diagonals, due to the insufficient strength of the connections. The typology (iii) refers to the rack with cable bracings that has exhibited a very high strength, and the test had to be stopped before failure due to the jack capacity.

\section{Conclusions}

This study presents the results of real scale push-over tests performed on fully-loaded braced steel storage rack specimens. From the capacity curves, global ductility of six commonly adopted storage rack typologies is quantified in terms of behaviour factor (q) values. The $q$ values of the racks that showed a global ductile behaviour range from 2.5 to 2.6, thanks to the diffuse exploitation of plastic resources in the spine bracings, the rest of the structural elements (uprights, pallet beams) remaining undamaged. On the other hand, the $\mathrm{q}$ values of the racks that had a global brittle collapse are equal to 1.0. In the latter case, it is also seen that experimental values of $\mathrm{q}$ were lower than their design values. When a rack non regular in plan is designed using a behaviour factor larger than 2.0, an experimental assessment or a 3D numerical pushover analysis validated with experimental calibration should be required. In these cases, refined finite element beam formulations would be also useful to account for the warping effects in mono-symmetric cross-section uprights. A parallel numerical study has shown the importance of warping effects for unbraced racks [45], and another one is underway which is based on the results of these tests with spine bracings.

This study demonstrates that during design, sufficient overstrength should be guaranteed for the bracing connections in order to avoid a global brittle collapse caused by sudden failure of the spine bracing-rack connections, such as bolt shear and bolt bending failures. Moreover, to avoid bolt-bearing, designers should consider enough distance between the bolt and the edge of the bracing, in conjunction with the general rule for bolted connections requiring the bolt's strength at least 20\% larger than the bearing strength. The results of these tests confirmed the possibility to design braced racks using relatively high behaviour factors of low ductility class, provided that the early connection failure is prevented.

Global torsion can be minimized either reducing the eccentricity/distance between the vertical bracing plane and rack, and/ or using horizontal bracing configurations where both the uprights and the spine bracing planes are connected, assuring an 

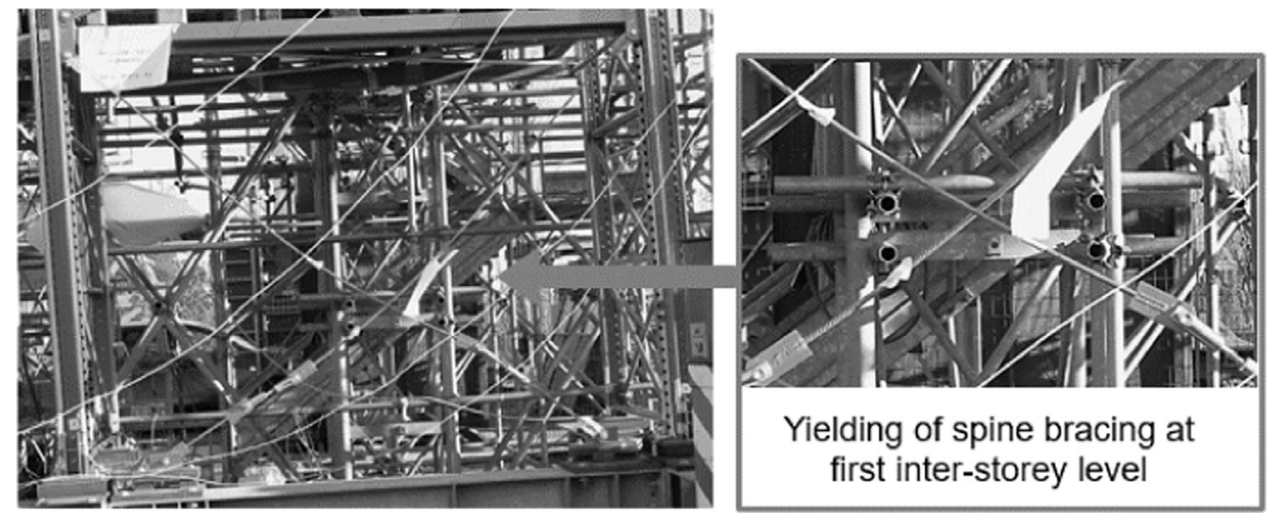

Fig. 21. Specimen IPA2: deformations of bracing elements at the end of the test.

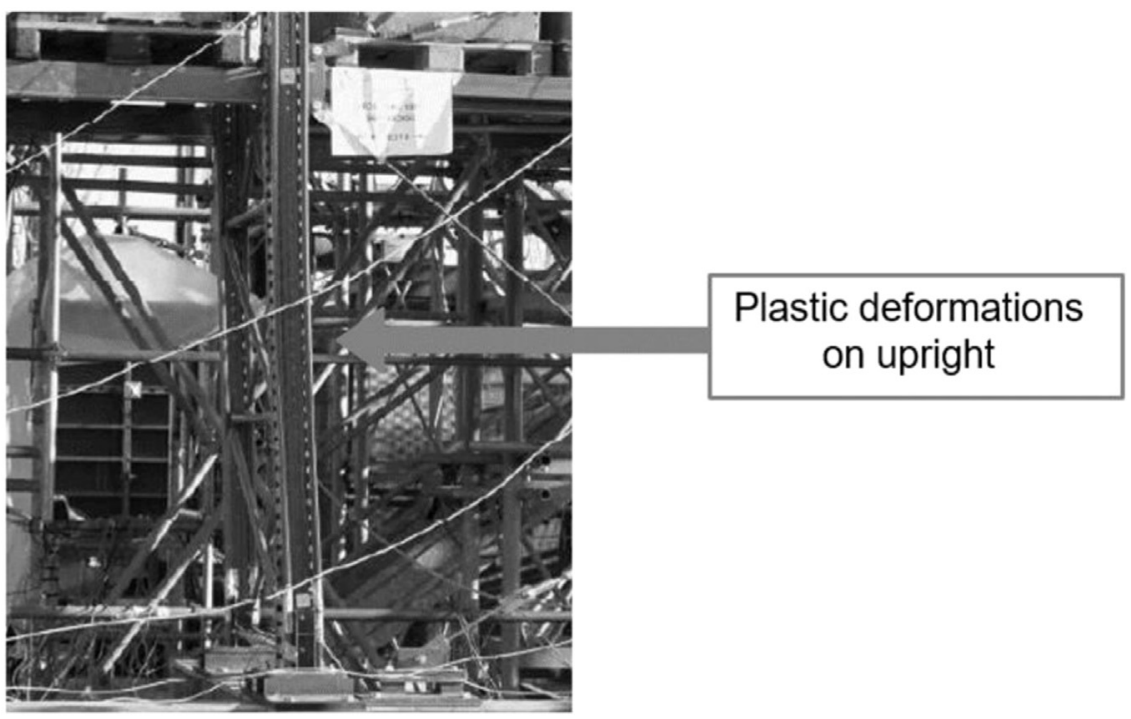

Fig. 22. Specimen IPA2: deformed shape of spine bracing upright.

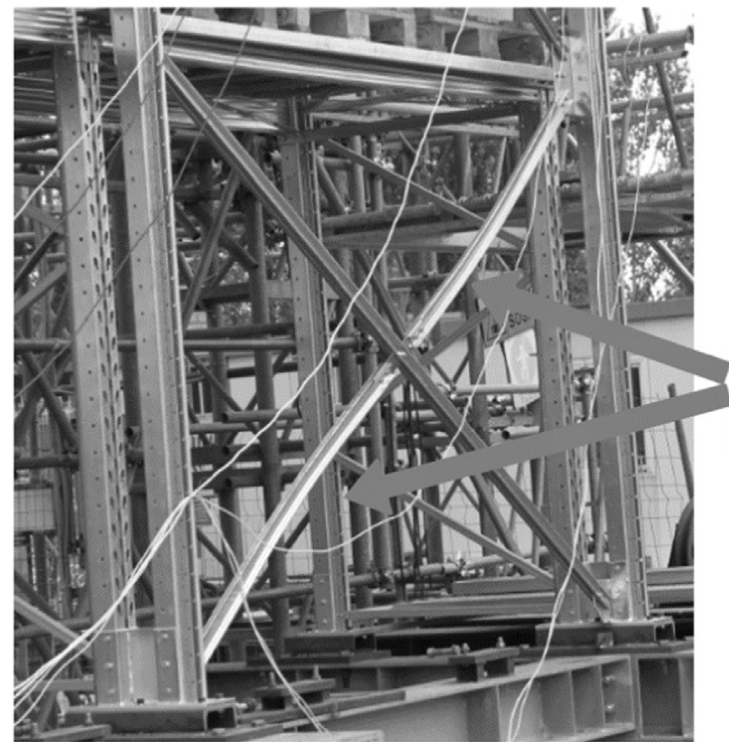

Buckling of compressed spine bracing elements

Fig. 23. Specimen IPE2: deformed shape of spine bracing at first inter-story level. 


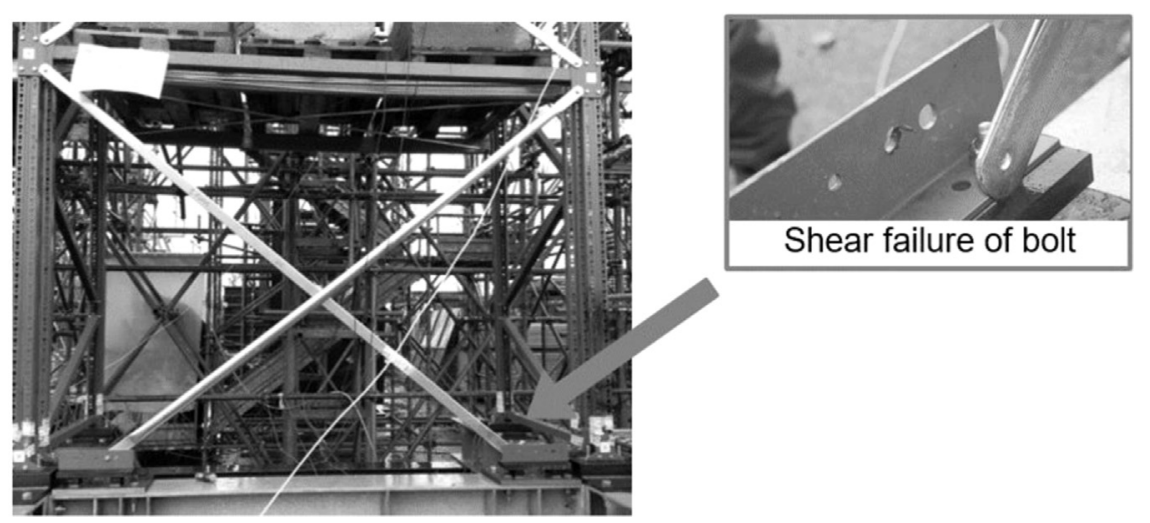

Fig. 24. Specimen IPB2: final configuration of spine bracing at failure load.

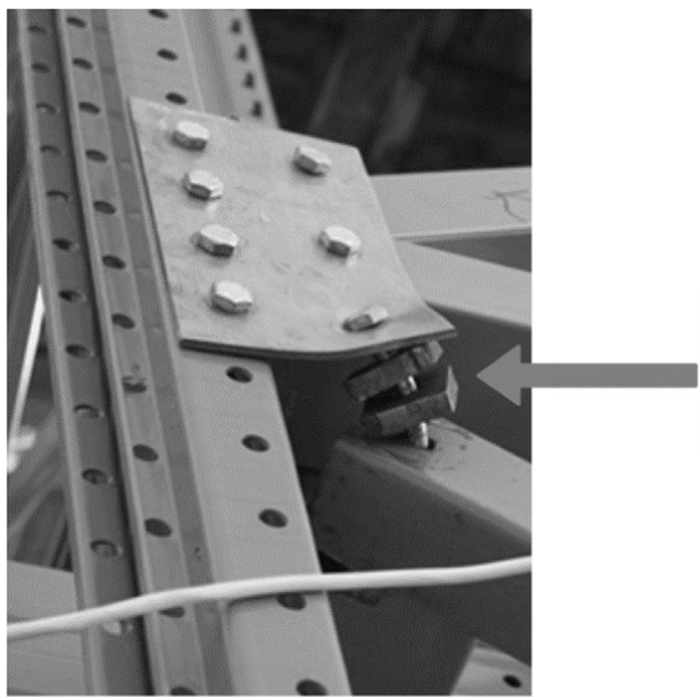

Flexural deformations of
bolt and external plates
during test

Fig. 25. Specimen IPD2: connection between upright and spine bracing.

Table 8

q-Factor values of braced racks.

\begin{tabular}{lllllll}
\hline & IPA2 & IPB2 & IPC2 & IPD2 & IPE2 & IPF2 \\
\hline$\Omega$ & 1.13 & 1.00 & NA & 1.00 & 1.18 & 1.15 \\
$\mathbf{q}$ & 2.19 & 1.00 & NA & 1.00 & 2.22 & 2.17 \\
$\mathbf{q}$ & $\mathbf{2 . 4 8}$ & $\mathbf{1 . 0 0}$ & NA & $\mathbf{1 . 0 0}$ & $\mathbf{2 . 6 1}$ & $\mathbf{2 . 5 0}$ \\
$q / q_{D E S I G N}$ & 1.65 & 0.67 & NA & 0.67 & 1.74 & 1.66 \\
\hline
\end{tabular}

efficient load transfer between these two. On the other hand, connecting the spine bracing plane only to the uprights at one side result in higher global torsional deformations, and should be avoided.

\section{Acknowledgements}

This article presents the results of full scale tests performed within SEISRACKS2 project, which is carried out with the financial grant of the Research Program of the Research Fund for Coal and Steel of the European Commission (RFSR-CT-2011-00031). Hard work of Master thesis student Marco Angeretti during the implementation of tests is deeply appreciated. Precious comments of Prof. Claudio Bernuzzi, and the efforts of the Industrial Partners of the SEISRACKS2 project, who helped us improving the quality of the article, are deeply appreciated.

\section{References}

[1] T. Pekoz, G. Winter, Cold-formed steel rack structures. Proc., 2nd Specialty Conference on Cold-Formed Steel Structures, (1973) 603-615.

[2] C. Bernuzzi, European and United States approaches for steel storage pallet rack design: part 1: discussions and general comparisons, Thin-Walled Struct. 97 (2015) 308-320.

[3] FEM 10.2.08, Recommendations for the Design of Static Steel Pallet Racking in Seismic Condition, Federation Europeen de la Manutention, Decembre 2005.

[4] Steel static storage systems - Adjustable pallet racking systems - Principles for seismic design, CEN/TC 344, prEN 16681:2016.

[5] P. Carydis, C. Castiglioni, E. Lekkas, I. Kostaki, N. Lebesis, A. Drei, The Emilia Romagna, May 2012 earthquake sequence. The influence of the vertical earthquake component and related geoscientific and engineering aspects. Ingegneria Sismica, Pavia, XXIX, N.2-3, April-Sept 2012, pp. 31-58.

[6] EPICentre Field Observation Report No. EPI-FO-290512, The 29th May 2012 Emilia Romagna Earthquake, UCL Department of Civil, Environmental and Geomatic Engineering, 21/06/2012.

[7] EN1998-1-1, Design of Structures for Earthquake Resistance, 2005.

[8] C. Bernuzzi, C.A. Castiglioni, Experimental analysis on the cyclic behaviour of beam-to-column joints in steel storage pallet racks, Thin-Walled Struct. 39 (2001) 841-859.

[9] N. Baldassino, C. Bernuzzi, Analysis and behaviour of steel storage pallet racks, Thin-Walled Struct. 37 (4) (2000) 277-304.

[10] N. Baldassino, R. Zandonini, Numerical and experimental analysis of baseplate connections of steel storage pallet racks, Proceedings of XVIII Conference C.T.A., Venezia, 2001, 127-136.

[11] N.W. Murray, Numerical and experimental analysis of base-plate connections of steel storage pallet racks, in: Proceedings of XVIII Conference C.T.A., Venezia, 2001, 127-136.

[12] B.P. Gilbert, K.J.R. Rasmussen, Determination of the base plate stiffness and strength of steel storage racking system, J. Constr. Steel Res. 67 (6) (2011) 1031-1041.

[13] B.P. Gilbert, K.J.R. Rasmussen, Bolted moment connections in drive-in and 
drive-through steel storage racks, J. Constr. Steel Res. 66 (6) (2010) 755-766.

[14] R. Kotha, T. Peköz, Cold-Formed Steel Frame and Beam-Column Design, School of Civiland Environmental Engineering, Cornell University, 2000.

[15] John A. Blume \& Associates, Seismic design examples of industrial storage racks, Report prepared for the Rack Manufacturer's Institute, San Francisco CA., 1973.

[16] H. Krawinkler, N.G. Cofie, M.A. Astiz, C.A. Kircher, Experimental study on the seismic behaviour of industrial storage racks, Report No. 41, The John A. Blume Earthquake Engineering Center, Department of Civil Engineering, Stanford University, Stanford CA., 1979.

[17] C.K. Chen, R.E. Scholl, J.A. Blume, Seismic study of industrial storage racks, Report prepared for the National Science Foundation and for the Rack Manufacturers Institute and Automated Storage and Retrieval Systems (Sections of the Material Handling Institute), John A. Blume \& Associates, San Francisco CA, 1980.

[18] A. Filiatrault, Shake-table tests of storage racks and contents, Presentation material at the April 12, 2001 Seismic Safety Commission Hearing on Industrial Storage Racks, San Francisco, CA, 2001.

[19] A. Filiatrault, A. Wanitkorkul, Shake-Table Testing of Frazier Industrial Storage Racks, Report No. CSEE-SEESL-2005-02, Structural Engineering and Earth-quake Simulation Laboratory, Departmental of Civil, Structural and Environ-mental Engineering, University at Buffalo, State University of New York, 2004.

[20] B. Gilbert, K. Rasmussen, Drive-in steel storage racks i: stiffness tests and 3D load-transfer mechanisms, J. Struct. Eng. 138 (2) (2012) 135-147.

[21] C.A. Castiglioni, Dynamic tests on steel pallet racks, Costr. Met. 55 (3) (2003) $35-44$.

[22] SEISRACKS RFSR-CT-2004-00045, Final Report, Research Program of the Research Fund for Coal and Steel RTD, May 2007.

[23] C.A. Castiglioni, A. Drei, P. Carydis, H. Mouzakis, Experimental assessment of static friction between pallet and beams in racking systems, Journal of Building Engineering (2016) http://dx.doi.org/10.1016/j.jobe.2016.03.004.

[24] C.A. Castiglioni, Seismic Behavior of Steel Storage Pallet Racking Systems, First ed., Springer International Publishing, Berlin, Germany, 2016 (ISSN 2198-7300)

[25] A. Castiglioni, A. Kanyilmaz, A. Drei, B. Hoffmeister, C. Heinemeyer, H. Degee C. Braham, I. Vayas, K. Adamakos, S. Sesana, B. Orsatti, The "SEISRACKS2" EURFCS Research Project "Seismic Behaviour of Steel Storage Pallet Racking Systems" - Part 1: Project Overview, XXIV Giornate Italiane Della Costruzione, Acciaio, Torino, Italia, 2013.

[26] A. Castiglioni, A. Kanyilmaz, A. Drei, B. Hoffmeister, C. Heinemeyer, H. Degee C. Braham, I. Vayas, K. Adamakos, N. Papadopoulos, The "SEISRACKS2" EU-RFCS Research Project "Seismic Behaviour of Steel Storage Pallet Racking Systems" Part 2: Experimental Activities, XXIV Giornate Italiane Della Costruzione, Acciaio, Torino, Italia, 2013.

[27] A. Castiglioni, A. Kanyilmaz, A. Drei, B. Hoffmeister, C. Heinemeyer, H. Degee, C. Braham, I. Vayas, K. Adamakos, S. Sesana, B. Orsatti, The "SEISRACKS2" EURFCS Research Project, Seismic Behavior of Steel Storage Pallet Racking
Systems, Costruzioni metalliche, January 2015.

[28] A. Kanyilmaz, C.A. Castiglioni, G. Brambilla, G. Chiarelli, Experimental assessment of the seismic behavior of unbraced steel storage pallet racks, ThinWalled Struct. (2016) (in preparation).

[29] DIN-EN 13698-1, Pallet production Specifications, Part 1: Construction specification for $800 \mathrm{~mm} \times 1200 \mathrm{~mm}$ flat wooden, 2004 .

[30] Seismic Considerations for Steel Storage Racks Located in Areas Accessible to the Public FEMA 460 - September 2005, National Institute of Building Sciences Washington, D.C., 2005.

[31] FEM 10.2.04, Users Code, Federation Europeenne de la Manutention, Section X Equipment et Proceedes de Stockage, 2001.

[32] FEM 10.2.03, Specifiers Guidelines, Federation Europeenne DE La Manutention, Section X, Equipment ET Proceedes DE Stockage, 2000.

[33] FEM 10.2.05, Guidelines for working safely with lift trucks in pallet racking installations, Federation Europeenne DE La Manutention, Section X, Equipment ET Proceedes DE Stockage, 2001.

[34] FEM 10.2.06, Design of Static Steel Shelving, Federation Europeenne DE La Manutention, Section X, Equipment ET Proceedes DE Stockage, 2001.

[35] EN 15512, Steel static storage systems - Adjustable pallet racking systems Principles for structural design, 2009.

[36] A.K. Chopra, R.K. Goel, A Modal Pushover Analysis Procedure to Estimate Seismic Demands for Buildings: Theory and Preliminary Evaluation, Report No. PEER 2001/03, Pacific Earthquake Engineering Research Center, University of California, Berkeley, 2001.

[37] FEMA-440, Improvement of Nonlinear Static Seismic Procedures, Applied Technology Council (ATC-55 Project), June 2005.

[38] G. D'Annibale, Fotogram: restituzione di modelli 2D e 3D da sorgenti fotografiche, D. Flaccovio, Palermo IT, 2003.

[39] $\mathrm{N} \mathrm{ECCS}^{\circ} 45$ Recommended Testing Procedure For Assessing the Behaviour of Structural Steel Elements under Cyclic Loads, Technical Committee 1 Structural Safety and Loadings Technical Working Group 1.3 - Seismic Design, 1986.

[40] N.M. Newmark, W.J. Hall, Earthquake spectra and design, EERI Monograph Series, EERI, Oakland, 1982

[41] ATC-34, A Critical Review of Current Approaches to Earthquake-Resistant Design, Applied Technology Council, Redwood City, CA, 1995.

[42] ATC-63, Quantification of Building Seismic Performance Factors, Applied Technology Council, Redwood City, CA 2008, pp. 6-31.

[43] G. Ballio, C.A. Castiglioni, An approach to the seismic design of steel structures based on cumulative damage criteria, Earthq. Eng. Struct. Dyn. 23 (1994) 969-986.

[44] H. Krawinkler, A.A. Nassar, Seismic design based on ductility and cumulative damage demands and capacities, in: P. Fajfar, H. Krawinkler (Eds.), Nonlinear Seismic Analysis of RC Buildings, Elsevier Science, New York, 1992, pp. 23-40.

[45] G. Gabbianelli, A. Kanyilmaz, C. Bernuzzi, C.A. Castiglioni, Combined experimental-numerical study on unbraced pallet racks under pushover loads, Ing. Sismica (2016) (in preparation). 